\title{
Service and Document Based Interoperability for European eCustoms Solutions
}

\author{
Tobias Vogel ${ }^{1}$, Alexander Schmidt $^{2}$, Alexander Lemm $^{3}$ and Hubert Österle \\ ${ }^{1}$ University of St. Gallen, Institute of Information Management, Tobias.Vogel@unisg.ch \\ ${ }^{2}$ SAP Research CEC St. Gallen, Alexander.Schmidt@sap.com \\ ${ }^{3}$ Technische Universität Darmstadt, Alexander.Lemm@is.tu-darmstadt.de \\ ${ }^{4}$ University of St. Gallen, Institute of Information Management, Hubert.Oesterle@unisg.ch
}

Received 29 April 2008; received in revised form 5 September 2008; accepted 7 October 2008

\begin{abstract}
Innovative eCustoms solutions play an important role in the pan-European eGovernment strategy. The underlying premise is interoperability postulating a common understanding of processes, services and the documents that are exchanged between business and government organizations as well as between governmental authorities of different EU member states. This article provides a stringent approach for deriving documents and services from current eCustoms procedures based on the UN/CEFACT standards framework and for embedding these in a service oriented architecture for Collaborative eGovernment. In doing so, we put a special focus on document engineering by applying the UN/CEFACT Core Component Technical Specification (CCTS), a conceptual framework for modeling document components in a syntax neutral and technology independent manner. By relying on CCTS, we want to tackle the challenge of handling different document configurations imposed by divergent national legislations, different customs procedures (export, import, transit, and excise) and different industries. The resulting conceptual model is transferred to XML schema serving as a basis for Web Services design and implementation. These Web Services are designed for seamless interoperable exchange of electronic customs documents between heterogeneous IS landscapes both on business and government side. Beyond the theoretical deduction practical insights are gained from a European research project implementing the artifacts proposed in a real-world setting.
\end{abstract}

Key words: eGovernment, Interoperability, eCustoms, Standards, Service Oriented Architecture, Web Services

Tobias Vogel Alexander Schmidt Alexander Lemm Hubert Österle 


\section{Introduction}

\section{1 eCustoms as a Main Pillar of the Pan-European eGovernment Strategy}

Leveraging information and communication technology (ICT) in the field of public administration (eGovernment) is regarded as a mission critical factor for achieving growth and competitiveness in Europe [88] p. 2. Global competitiveness of businesses is significantly influenced by transaction costs incurred in dealing with public administrations [17] p. 21. In the process of creating the prerequisites for better and more efficient public administration, eGovernment is considered to be an enabler as it incorporates the use of information and communication technologies combined with organizational change in order to improve public services [17] p. 7.

At best, successful eGovernment solutions are intended to be beneficial to both public administrations and businesses [92] p. 345. However, eGovernment initiatives have to face the challenge of Business-to-Government (B2G) and Government-to-Government (G2G) integration, comprising seamless exchange of information, interoperation of independent eGovernment information systems, and coordination of governmental processes on the one side with information systems and processes of the economic operators on the other side [70] p. 889. This requires interoperability within or between organizations (be it public or private), nationally or across Europe [17] $\mathrm{p}$. 19. In the following we will put our focus on seamless B2G integration. Regarding B2G, Krcmar and Wolf have introduced the notion of 'Collaborative eGovernment', which postulates seamless integration of eBusiness infrastructures of enterprises with information systems of administrations from an end-to-end process perspective [91] p. 179. More specifically, we will inquire the interaction between economic operators and government agencies in the context of European eCustom procedures.

Regarding eCustoms procedures, Baida et al. point out that crucial EU control procedures are still paper based [3] p. 12. Hence, new customs control procedures are required which can be supported much more effectively and efficiently by the use of IT. However, designing and implementing changes in customs control procedures has to take into account technological, financial and political issues and has to balance between greater security demands in international trade and reduction of administrative work. Meeting both these objectives is generally perceived as a dilemma (cp. [3] p. 1) that can only be dissolved by process integration on the basis of seamless exchange of customs information between economic operators and national customs authorities as well as among national customs authorities.

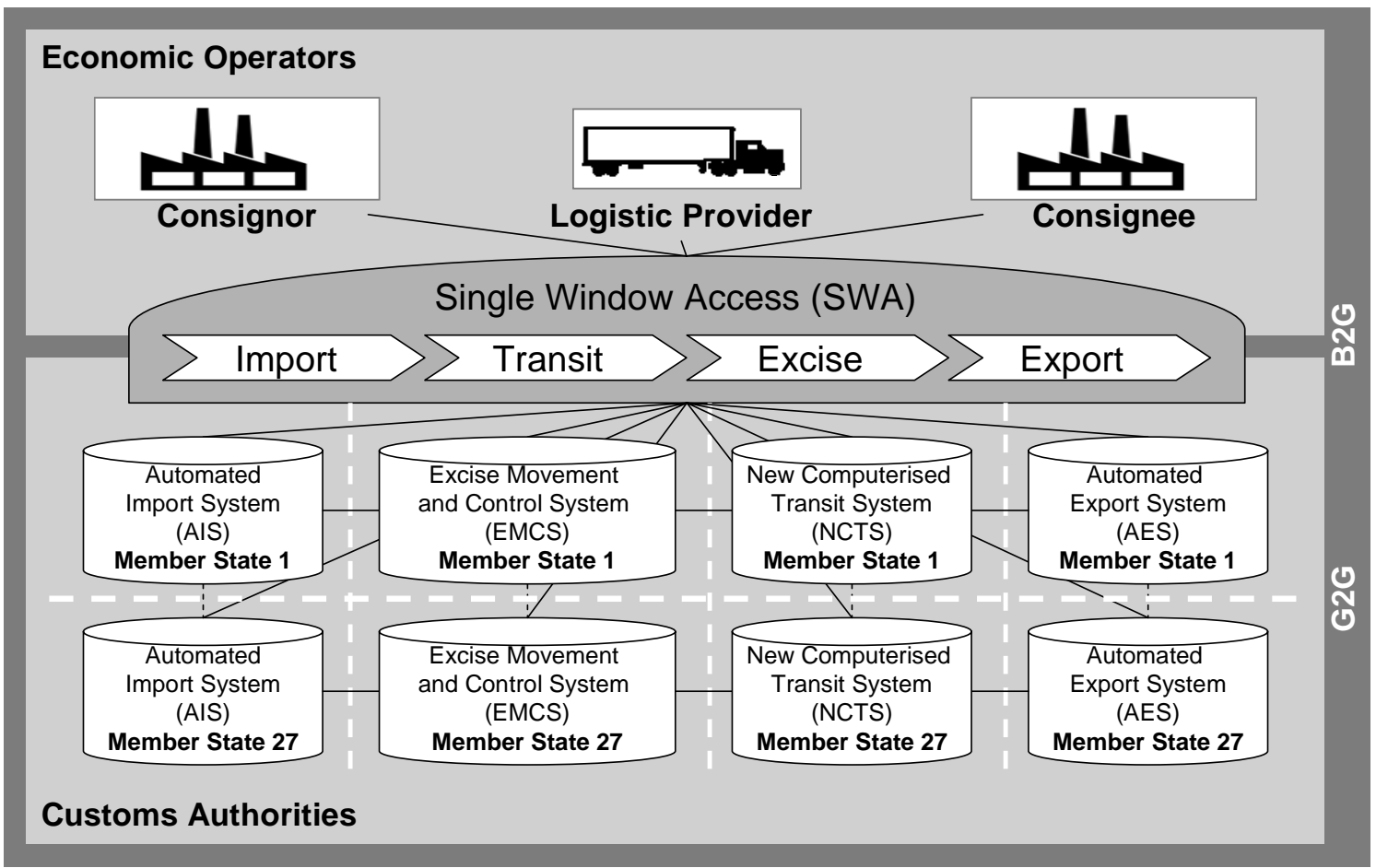

Figure 1: Envisioned Single Window Access Concept

Therefore, the European Commission has issued the Electronic Customs Multi-Annual Strategic Plan (MASP) [18], pointing out the objectives of a European wide eCustoms strategy. On the one hand, the EU aims at operational efficiency by reducing administrative burdens and improving clearance times of customs procedures. On the other hand, the EU focuses on achieving control effectiveness in increasing security of trade and safety of goods as well 
as enhancing health and environmental protection while safeguarding intellectual property and preventing fiscal fraud [18] p. 5. The centerpiece of MASP is the so-called Single Window Access (SWA) concept, which means that traders have access to a single electronic point for import, transit, excise and export transactions, irrespective of the member state in which the transaction starts or ends [18] p. 6. The SWA concept provides a 'single point of access' to existing and future computerized customs systems of the respective member states. This can only be achieved by integration of existing community customs procedures and systems, such as the New Computerised Transit System (NCTS) and future systems such as the Automated Export System (AES), the Automated Import System (AIS) and the Excise Movement and Control System (EMCS) with the ERP systems of the economic operators.

\subsection{Information Technology for Adoption and Intelligent Design for eGovernment (ITAIDE)}

The ITAIDE project is a European research project funded by the European Commission under the 6th Framework Information Society Technology (IST) programme with the objective to develop innovative eCustoms solutions [40]. ITAIDE started in January 2006 and will end in June 2010. The ITAIDE consortium consists of tax and customs administrations, IT providers, multi-nationals from different sectors, the standardization body of the United Nations, and European universities from the Netherlands, Germany, Denmark, and Finland. The ITAIDE project aims at developing recommendations, models, methods, and tools for a more effective and efficient exchange of taxation and customs information. The goal is to lower the administrative burden for economic operators while at the same time meeting tightened control, security and transparency requirements of public administration in international trade. From a business perspective, research is being conducted by developing a procedure redesign methodology for simplified customs and taxation procedures and elaborating a network collaboration model for developing privatepublic partnerships between customs and taxation offices, business and technology providers for more effective provisioning of public administration eServices [40] p. 6.

From an information system perspective, a common information model for electronic trade documents based on existing international standards from UN/CEFACT, World Customs Organization (WCO), and EU-DG Taxation \& Customs in combination with service oriented concepts and standards will form the foundation for ensuring a technically and semantically interoperable exchange of business documents between different eCustoms applications throughout Europe [40] p. 8. As depicted in Figure 2, the underlying premise in achieving this aim is pan-European interoperability enforcing a common understanding and mutual agreement on a technical, procedural and organizational level between businesses and governments as well as between governmental authorities of the different member states.

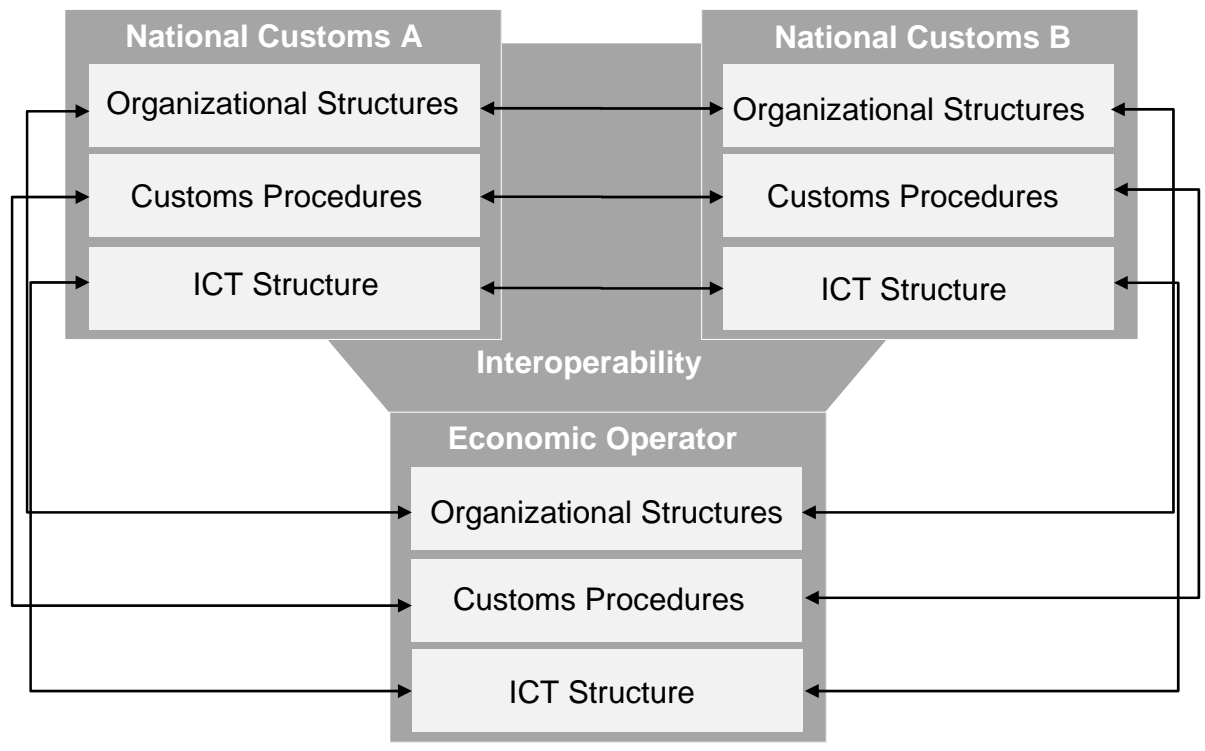

Figure 2: Conceptual Framework for Pan-European Interoperability

In order to validate the theoretical research artifacts elaborated within the project, ITAIDE avails itself of the Living Lab concept [78]. Four European Living Labs provide the real-life settings in which the eCustoms solutions are being developed and their broader influence on diffusion and adoption is being investigated. One of these Living Labs is the Beer Living Lab (BLL), where the shipment of beer outside the EU (export) and within the EU (intra-community supplies) is being examined. Products such as alcohol, tobacco or energy products are subjected to excise duties, which are indirect taxes on consumption of certain products that are raised in the country of consumption. In our article we refer to the application scenario for intra-EU movement of excise goods as the beer transport is subjected to duty suspension in the country of origin. 


\subsection{Outline of the Article}

The contribution of our research as presented in this article will be twofold. First, we will provide an approach for deriving customizable business documents and services from current eCustoms procedures based on UN/CEFACT standards. Second, we will embed these artifacts in a collaborative eGovernment architecture encompassing an information, a service and a process model for B2G and G2G interoperation as demanded by [70] and [91]. In doing so, we want to contribute to the concept of Single Window Access as proposed by the European Commission. Our research work is part of the ITAIDE project, namely Work Package 1 'Document and Message Standards' and Work Package 2 'Application Interoperability Validation' [40]. The feasibility of the solution is being evaluated in the Beer Living Lab, which has been adopting the results of procedure redesign efforts of [3] in order to derive corresponding information systems (IS) artifacts in terms of business documents and services.

The article is structured as follows: In Chapter 2 we will refer to the state of the art of related research in the field, before we will specify the research method we have applied. In Chapter 3 we will set forth the conceptual foundations our approach is based on. A presentation of our approach will be given in Chapter 4 . Thereafter in Chapter 5, the application scenario concerning the aforementioned Beer Living Lab will serve as a proof of concept. Finally, Chapter 6 will give a short summary and discussion on the insights which we have gained from our research and reveals their impact on further research.

\section{Prior Research}

The need for cross-organizational integration entails interoperability. Interoperability in turn implies a common understanding of cross-organizational business processes as well as roles, generally accepted design principles of business documents, and, finally, services by which business documents are supposed to be exchanged [46]. The following paragraphs will outline the insights gained from numerous research efforts, which have been conducted in domains relevant to our own research.

\subsection{Aspects of Cross-Organizational Integration and Interoperability}

Putting eGovernment strategies and objectives into practice demands higher levels of integration [89]. Layne and Lee argue that for developing more efficient and effective eGovernment services both vertical integration of systems with similar functionalities and horizontal integration of systems across different functions and departments is required [44]. This calls for interoperability of information systems and the processes that are supported by these information systems [23], [42].

Regarding interoperability, we follow [37], defining interoperability as the capability of ICT systems and of the business processes they support to exchange data and to enable the sharing of information and knowledge. More specifically, Scholl and Klischewski define eGovernment interoperability as the capability for direct machine-tomachine interaction in Business-to-Government (B2G) as well as Government-to-Government (G2G) [70].

Due to the intense research interest in interoperability, several frameworks for interoperability have emerged in recent years [48]. In the context of eGovernment interoperability, two prominent examples are the European Interoperability Framework and the R4eGov Interoperability Framework. The European Interoperability Framework takes a holistic view on interoperability by distinguishing between three levels of agreement (organization, semantics, and technique) on which interoperability issues have to be addressed [37]. The even more comprehensive R4eGov Interoperability Framework takes three dimensions into consideration: (1) interoperability at a technical, a semantic and an organizational level, (2) seamless eAdministration over cross-functional domains, and (3) organizational hierarchy (local, national, EU wide) [14].

Standardization constitutes the pivotal enabler of interoperability. EDI/EDIFACT communication standards have been fostering two-way machine-to-machine B2G and G2G interoperability. For instance, both the current eCustoms system in the Netherlands called Sagitta and the German ATLAS system process EDIFACT messages [39] p.183. But EDIFACT fails to achieve full interoperability due to the missing standardization of semantics (meaning and usage of business document content) and pragmatics (definition of inter-organizational process flow) of crossorganizational interaction [43], [54]. Furthermore, classic forms of EDI are restricted to high-volume interactions, as adoption is regarded as complex and expensive due to bilateral adjustments [7] and constant evolution [11].

\subsection{Design and Adaptation of Business Documents}

Within the B2B integration domain, message or document orientation has always played an important role [9], [50] pp. 152. So-called eBusiness frameworks - both XML-based (OAGIS, OASIS UBL, CIDX, etc.) as well as EDIFACTbased (EANCOM, Odette, ANSI ASC X12, etc.) - put a strong emphasis on the definition of business documents [58]. Hence, the design of business documents is crucial, but document oriented B2B standards provide no consistent and standardized methodology how to identify and design business documents [41] pp. 75 - 76. 
One approach which takes this concern into account is the document engineering approach of Glushko and McGrath defining document engineering as an interdisciplinary approach to develop analysis and design methods for specification, design, and implementation of documents exchanged between independent business processes [31]. They argue that the necessity of document engineering gains momentum with the diffusion of service oriented paradigms, as documents are the input and output of business services [30] p. 5. In leveraging business services, it is possible to coordinate business processes between business partners in a loosely coupled manner by the exchange of documents [30] p. 9. From a process perspective, documents describe the interface to business processes [30] p. 21.

With respect to interoperability, document engineering entails the need for standardization of syntax, structure, and semantics of business documents and their reusable components. Until some time ago, standardization efforts in the XML-based business document realm were dominated by vertical standardization organizations in order to meet requirements of specific industries, such as CIDX for the chemical, RosettaNet for the high-tech, and SWIFT for the banking industry [57], [95]. More current efforts have been trying to define a common set of business documents (OAGIS, OASIS UBL) that can be used in different contexts by providing mechanisms to allow controlled customization and extensibility of business documents. In doing so, these approaches are trying to meet specific demands while still relying on a common information set facilitating reuse and compatibility. UN/CEFACT contributes to these aspects by delivering a set of standards for business document interoperability and adaptability, namely the Core Component Technical Specification and its adjacent specifications, as well as the Unified Context Methodology (UCM), which allows context based modeling in accordance with [5]. Especially the OASIS UBL 2.0 is considered to be the first XML based standard to be compliant to the CCTS specification [60]. UBL supports procurement scenarios in the public sector [93] as well as simple international trade processes. As there has been a strong alignment between UN/CEFACT and OASIS UBL since 2005 [84], we restrict ourselves to CCTS (cp. [49] p. 77).

These approaches together with the aforementioned principles of document engineering are essential for our own approach and will be presented in more detail in chapter 3 and chapter 4 .

\subsection{Service Oriented Architecture and Web Services}

A service oriented architecture (SOA) is a multi-layer distributed IS architecture, which evolves existing approaches of designing distributed application systems such as Client/Server or component oriented paradigms [1] pp. 131, [73]. [27] considers service orientation as an architecture style of its own. The SOA concept aims at providing a stronger alignment of the business process architecture with the underlying IS architecture [67].

In doing so, services structure and encapsulate data and functions of the application system layer behind a welldefined, stable interface to meet the requirements of business processes and to foster reuse [16] p. 282. According to [56], a service specification is considered as a triplet $P=(D ; M ; O)$, where $D$ is the set of data types of the service, $M$ is the set of messages or business documents exchanged as part of operation invocations, and $O$ is the set of operations supported by the service. The design of services is considered to be a critical point. Based on a broad literature review Legner and Heutschi identify four fundamental principles of service design [45]: (1) separation of interface logic and implementation logic, (2) interoperability through technical and business standards, (3) loose coupling, and (4) process oriented service identification.

Although Web Services are not the only instrument for implementing services in a SOA, they are preferred in heterogeneous environments because of their technical interoperability characteristics relying on open, standardized web technologies [80]. The World Wide Web Consortium defines a Web Service as 'a software application identified by a URI, whose interfaces and bindings are capable of being defined, described, and discovered as XML artifacts. A Web Service supports direct interaction with other software agents using XML-based messages exchanged via Internet protocols.' [87]. Web Services build on a number of open standards, in particular XML to tag data, SOAP to transfer data, and WSDL for service interface descriptions [1], [80].

Being an enhanced concept for integration in heterogeneous process and system landscapes, SOA is expected to foster inter-organizational process integration [12], [34]. As heterogeneity in technical and business terms rises at the borders of organizations, it is envisioned that in the future services could be leveraged to exchange electronic business documents in order to achieve process integration with business partners [13], [34], [63], [86].

Nevertheless, it has not yet been well understood how enterprises could leverage service oriented concepts in order to establish interoperable B2B, B2G or G2G relationships. Web Services only ensure interoperability on a syntactic level, while semantic and pragmatic aspects of cross-organizational integration are not taken into account [47], [54]. This is why interoperability is only guaranteed when using complementarily defined vertical industry or governmental standards. The challenge can be seen in deriving SOA artifacts out of such vertical business standards, namely the data model, the document, and the process choreography. The discussion on leveraging SOA and Web Services in cross-organizational integration has not yet been intensified in the academic discourse. Current research of [26], [28], [96] is discussing the application of SOA concepts and Web Service technology in dedicated B2B scenarios, while in the eGovernment realm both [2] and [55] adopt a Web Service oriented architecture solely for internal application integration. 


\subsection{Research Method and Questions}

The article at hand adopts Design Science as a research framework, which is recommended for scientific studying in the field of IT where artificial, human-made phenomena, such as organizations and/or information systems, are examined [53] p. 253. Consequently, IT artifacts capable of solving research problems in the information system realm constitute the centerpiece of Design Science research as they are both developed and evaluated [32] p. 629, [36] p. 77. The essential elements of the Design Science approach are summarized in seven guidelines propagated by [36]. The following table shows how we assign these guidelines to our research work.

Table 1: Applying Design Science to our Research Approach

\begin{tabular}{|c|c|}
\hline Guideline & Description and connection to our research \\
\hline $\begin{array}{l}\text { Design as an } \\
\text { Artifact }\end{array}$ & $\begin{array}{l}\text { We develop a model of a service based architecture for B2G and G2G collaboration and a } \\
\text { methodological approach for the systematic derivation of customizable business } \\
\text { documents and services on the basis of a collaborative public process. Architecture models } \\
\text { and methods are recognized as viable artifacts in information systems research [36] p. } 78 \text {. }\end{array}$ \\
\hline Problem Relevance & $\begin{array}{l}\text { The estimated annual cost-saving potential of EU-wide electronic B2G collaborations } \\
\text { exceeds } € 50 \text { billion [22]. More specifically, the significance of eCustoms becomes evident } \\
\text { against the background of current EU initiatives for making eCustoms procedures more } \\
\text { efficient, such as MASP and Single Window Access [18]. The need for the concepts } \\
\text { developed in this article is even increased if one considers the diversity of European } \\
\text { customs related systems and their nationally differing, mostly paper based implementation } \\
\text { [51] p. } 94 \text {. }\end{array}$ \\
\hline Design Evaluation & $\begin{array}{l}\text { The evaluation of the concepts elaborated is effected on the basis of a field study in the } \\
\text { context of the ITAIDE project by applying them in a real-world customs scenario (excise } \\
\text { movement in the beer industry) as a proof of concept. }\end{array}$ \\
\hline $\begin{array}{l}\text { Research } \\
\text { Contributions }\end{array}$ & $\begin{array}{l}\text { The scientific contribution of our research is threefold. Firstly, we apply the architecture } \\
\text { model we propose and our approach for deriving customizable business documents and } \\
\text { services to a real-world B2G scenario (in the area of customs) in order to demonstrate their } \\
\text { feasibility. Secondly, we give proof of the applicability of the CCTS approach for designing } \\
\text { and adapting business documents. Thirdly, we employ the Web Services concept to } \\
\text { implement a Service Oriented Architecture to increase cross-organizational interoperability } \\
\text { in the B2G and G2G domain. }\end{array}$ \\
\hline Research Rigor & $\begin{array}{l}\text { The design of the artifacts is based on established research methods (Context based/ } \\
\text { Conceptual Modeling, Document Engineering, Web Service Design) and systematically } \\
\text { enhances existing concepts. }\end{array}$ \\
\hline $\begin{array}{l}\text { Design as Search } \\
\text { Process }\end{array}$ & $\begin{array}{l}\text { The research results have been derived iteratively within the ITAIDE project over a period } \\
\text { of more than two years. Further iteration cycles will be started with the adoption of the } \\
\text { proposed concepts to other Living Labs of ITAIDE leading to a refinement of the approach } \\
\text { and prompting a more significant evaluation. }\end{array}$ \\
\hline $\begin{array}{l}\text { Communication of } \\
\text { Research }\end{array}$ & $\begin{array}{l}\text { The insights gained in our research as well as the concepts elaborated are being } \\
\text { disseminated to current eCustoms initiatives via the ITAIDE project and to ongoing } \\
\text { standardization efforts of the UN/CEFACT. }\end{array}$ \\
\hline
\end{tabular}

With Design Science serving as our general research framework, the article addresses the following research questions:

- What are the fundamental design principles of a Service Oriented Architecture for B2G and G2G collaboration in the eGovernment domain?

- How can we derive customizable business documents and services from current EU eCustoms procedures in a process oriented manner to foster interoperability and hence achieve B2G integration?

- Are UN/CEFACT standards suitable to increase reuse and customization of eCustoms business documents?

\section{Conceptual Foundations}

\subsection{The UN/CEFACT Standards Stack for Business Document Modelling}

The UN/CEFACT Core Component Technical Specification (CCTS) is a conceptual framework for modeling document components in the eBusiness realm in a syntax neutral and technologically independent manner [30] p. 80 and p. 455, [69], [71]. The UN/CEFACT CCTS specification 2.01 has its foundations in the ebXML initiative as part 5 of the ebXML framework and is recognized as ISO 15000-5 [38]. UN/CEFACT is currently developing the third 
version of the recommendation [82]. The specification itself is embedded in a stack of affiliated UN/CEFACT standards [77] as shown in Figure 3.
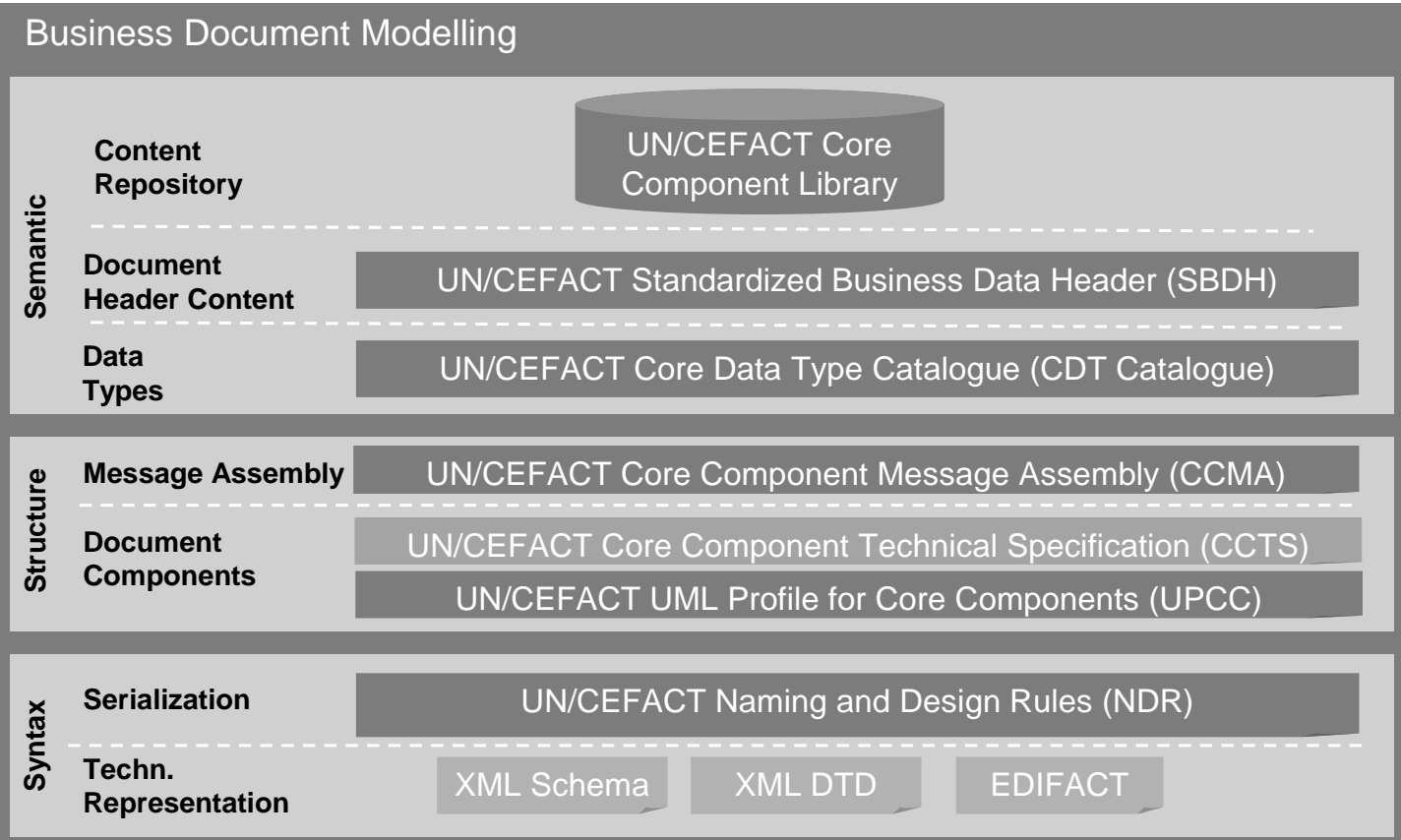

Figure 3: The UN/CEFACT eBusiness Standards Stack

The CCTS modeling approach aims at enhancing interoperability, reusability, and adaptability of document components. This requires a common understanding of document components, which is achieved by defining a conceptual meta model and naming and definition conventions for these document components [75]. Regarding the meta model, the CCTS distinguishes between the concept of Core Components and the concept of Business Information Entities (BIEs). Core Components are generic, abstract building blocks serving as a blueprint from which context specific BIEs are derived. Comparable to the concepts of object orientation (class, attribute, association), there are three types of BIEs: Aggregated Business Information Entities (ABIEs), which consist of one or more Basic Business Information Entities (BBIEs) as atomic attributes, and Associated Business Information Entities (ASBIEs) as complex attributes associating other ABIEs. By grouping BBIEs and ASBIEs to ABIEs, information entities are structured in a hierarchic way. Naming conventions as a set of rules governing the naming of BIEs are based on ISO 11179 part 5. Hence, all BIEs are specified by a Dictionary Entry Name (DEN) composed of three naming parts. The Object Class Term represents the object class which the BIE belongs to, the Property Term represents a distinguishing characteristic of the object class, and the Representation Term describes the format in which the component is represented. Relying on ISO 11179 Part 4 Definitions, each BIE has a unique identifier, a unique version identifier [82] p.56, a well-defined semantic definition and one or more additional business terms acting as synonyms, under which the BIE is commonly known and used in business for a specific context. Alongside with that, the BBIEs are typed by Business Data Types. These are the smallest and most generic pieces of information in a business data model [77]. The UN/CEFACT Core Data Type Catalogue [83] defines 21 syntax neutral, abstract Core Data Types for numerical values, codes, identification, dates, times, and textual information, on which the Business Data Types are defined.

Complementarily, the Standard Business Document Header (SBDH) specification provides meta information necessary to receive and process business documents. It is conveyed as the first part (i.e. header) of a business message to easily extract routing and contact information through key data elements, such as document type identifier, sender, recipient, and contact identifiers, and related metadata information [77]. Apart from that, the upcoming Core Component Message Assembly (CCMA) specification is supposed to provide guidelines for assembling the Standard Business Document Header and higher-level Business Information Entities to business documents.

Furthermore, the Core Component Library serves as a repository for approved Business Information Entities in terms of a canonical information model for cross-organizational communication. Currently, different International Trade and Business Processes Groups of UN/CEFACT, which are responsible for business and governmental requirements and content in dedicated domains, as well as external standardization organizations such as UBL or OAGi are supposed to submit their proposals to be included in the Core Component Library. Within UN/CEFACT, the Trade and Business Processes Group 17 (Harmonization Group) reviews and approves Business Information Entities that have been submitted to ensure harmonization and consistency of the Core Component Library. The Harmonization Group also checks compliance of the submissions with the CCTS specification. The latest version of the Core 
Component Library can be found at [81]. However, a closer look reveals that the Core Component Library is still in its initial phase, lacking both comprehensiveness and maturity.

Instead of defining a graphical notation on its own, CCTS relies on the complementary UN/CEFACT UML Profile for Core Components (UPCC) specification. As the concept of Business Information Entities and Business Data Types is syntax neutral, it requires translation to a deployable syntax. The UN/CEFACT XML Naming and Design Rules (NDR) are supposed to translate the CCTS artifacts into XML schema. Serialization rules for other syntax bindings such as UN/EDIFACT are easily conceivable, but have not emerged so far.

Currently, Warp10 [76] and the H2-Toolset [5] are research prototypes providing tool support for configuration and variant management of business document components according to the CCTS specification, particularly implementing a context driver mechanism, which will be explained in more detail in the following section.

\subsection{The Context Driver Principle}

As mentioned in Section 2.2, current research efforts put an increasing focus on providing context mechanisms, which allow flexible adaptation and customization of generally defined information blocks for specific business needs. Generally spoken, context mechanisms are intended to enrich information, which at a basic level consists only of a stream of data not carrying any additional semantic information, with business context [41] p. 62. Consequently, context is recognized as a key driver to precisely determine business meaning and semantics.

Regarding business document customization, context is used to identify the scope of application by defining circumstances and conditions under which particular document components are or are not relevant [5]. More precisely, [6] emphasize the significance of context for configuration of specific document or model variants through specification of multiple configuration parameters [6] p. 841. These configuration parameters in our case correspond to context categories (see following paragraphs).

The UN/CEFACT Context Methodology (UCM) project was initiated by UN/CEFACT with the purpose of remediating the lack of a formal context mechanism and developing a unified methodology and technical specification for discovering, registering and using context drivers. The foundations of UCM reach back to the context mechanisms specified in the CCTS Version 2.01. Although the artifacts, for which UCM is intended to be applied to, are both information model and business process model artifacts, we only consider its application to information model artifacts, i.e. for representing business contexts to Business Data Types and Business Information Entities and for customizing business documents during message assembly.

In [82] p.117 context is specified by a set of context categories (known as business context) and associated values enabling full semantic qualification of BIEs. The derivation of BIEs is always based on a restriction or specialization, meaning that the resulting qualified BIE represents a subset or restriction of its unqualified equivalent. This corresponds to the definition of context as a filter constraining available constructs [5] p. 148. Based on the CCTS specification, [62] and [94] developed a meta model of the context driver principle, which is outlined in Figure 4.

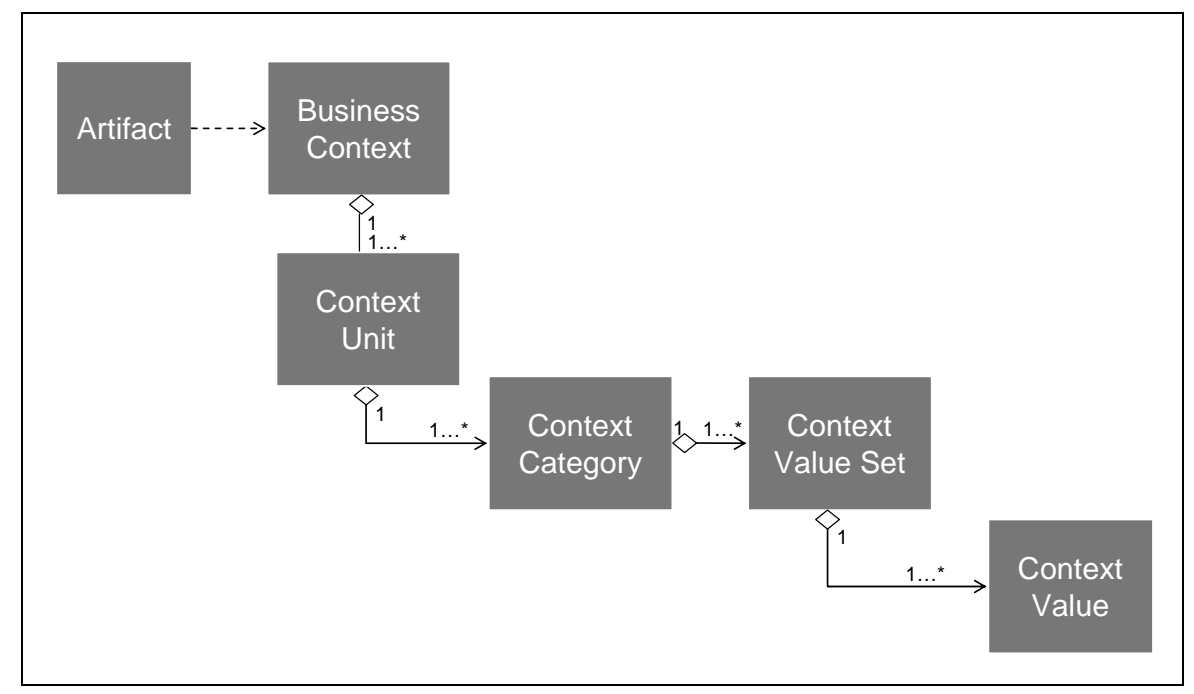

Figure 4: Meta Model of the Context Driver Principle

As illustrated in the meta model, a business context consists of a set of context units which in turn consist of a combination of context values of the respective context categories. For the contextualization of artifacts a predefined set of values needs to be assigned for each context category, with 'in all contexts' being an admissible value. The specification of values for the eight context categories defined by the UN/CEFACT should suffice to unambiguously 
describe the business context in which the business collaboration takes place. The values for each of the categories are provided by internationally recognized code lists, such as the Universal Standard Product and Service Specification (UNSPSC) for product classification, the International Standard for Industrial Classification (ISIC) for the industrial classification context category, or the ISO 3166.1 country code list for the geopolitical context.

Table 2 provides examples of possible context values for each of the eight context categories defined.

Table 2: Context Categories as Proposed by UN/CEFACT [82] pp. 116

\begin{tabular}{|c|c|c|}
\hline Context Category & Code List & Exemplary Context Values \\
\hline $\begin{array}{l}\text { Business Process } \\
\text { Context }\end{array}$ & $\begin{array}{l}\text { UN/CEFACT Catalogue } \\
\text { of Common Business } \\
\text { Processes }\end{array}$ & $\begin{array}{l}\text { EXMO (Excise Movement), TRDE (Transit } \\
\text { Declaration), CROR (Create Order), PRPA } \\
\text { (Process Payment) }\end{array}$ \\
\hline $\begin{array}{l}\text { Product Classification } \\
\text { Context }\end{array}$ & $\begin{array}{l}\text { Universal Standard Product and Service } \\
\text { Specification (UNSPSC), Standard } \\
\text { International Trade Classification (SITC) }\end{array}$ & $\begin{array}{l}50202200 \text { (Alcoholic Beverages), } 23152900 \\
\text { (Packaging Machinery), 25101500 } \\
\text { (Passenger Motor Vehicles), 53102500 } \\
\text { (Clothing Accessories) }\end{array}$ \\
\hline $\begin{array}{l}\text { Industry Classification } \\
\text { Context }\end{array}$ & $\begin{array}{l}\text { International Standard for Industrial } \\
\text { Classification (ISIC) }\end{array}$ & $\begin{array}{l}\text { AU (Automotive), CP (Consumer Products), } \\
\text { RT (Retail), PU (Public Sector) }\end{array}$ \\
\hline Geopolitical Context & ISO 3166.1 Country Code List & $\begin{array}{l}\text { BG (Bulgaria), NL (Netherlands), CH } \\
\text { (Switzerland), US (United States) }\end{array}$ \\
\hline $\begin{array}{l}\text { Official Constraints } \\
\text { Context }\end{array}$ & $\begin{array}{l}\text { No standardized } \\
\text { code list available yet }\end{array}$ & Title 20 Restriction (for import of beef) \\
\hline $\begin{array}{l}\text { Business Process Role } \\
\text { Context }\end{array}$ & $\begin{array}{l}\text { UN/CEFACT Catalogue of Common } \\
\text { Business Processes }\end{array}$ & $\begin{array}{l}\text { CN (Consignee), CA (Carrier), EX (Exporter), } \\
\text { SE (Seller), SU (Supplier) }\end{array}$ \\
\hline $\begin{array}{l}\text { Supporting Role } \\
\text { Context }\end{array}$ & $\begin{array}{l}\text { UN/CEFACT Catalogue of Common } \\
\text { Business Processes, UN/EDIFACT } \\
\text { Code List for DE } 3035 \text { Party Roles }\end{array}$ & $\begin{array}{l}\text { GB (Chamber of Commerce), IO (Insurance } \\
\text { Company), UD (Ultimate Customer), PQ } \\
\text { (Certifying Party) }\end{array}$ \\
\hline $\begin{array}{l}\text { System Capabilities } \\
\text { Context }\end{array}$ & $\begin{array}{l}\text { No standardized } \\
\text { code list available yet }\end{array}$ & $\begin{array}{l}\text { OASIS:UBL:V2.0, SAP:GDT:2.0, } \\
\text { OAGIS:BODs:V9.1, } \\
\text { UNECE: EDIFACT:D.07A, } \\
\text { GS1:RosettaNetPIPs:3.0 }\end{array}$ \\
\hline
\end{tabular}

As the UCM project is still in a preliminary stage at this point of time, the following work is based on the context definition of the Core Component Technical Specification Version 3.0 [82]. The finalization and publication of the UCM specification of the context mechanism is envisaged for 2009.

\section{Research Artifacts}

\subsection{Architectural Overview}

Serving as a frame of reference, this paragraph will elaborate the concept for a service based architecture for B2G collaboration, enhancing existing enterprise architecture approaches, such as [29], [52], [61], [90]. In doing so, the architecture relies on two fundamental design principles for handling complexity and heterogeneity in enterprise architectures, namely layer formation as vertical and view formation as horizontal separation of concerns. The basic principles of our architecture are outlined in Figure 5.

Current enterprise architectures fail to systematically and explicitly identify and describe design elements on the process and the system layer of cross-organizational integration [46]. But if the appropriate design elements are added to each of the three layers, it is reasonable to distinguish between design elements of the internal view ('private') and design elements of the external, cross-organizational view ('public'). The reason for this distinction lies in cross-organizational decoupling, as an organization's internal process and IS architecture is designed and evolves independently of the ones of its partners. Inter-organizational process and system integration however involves complex implementation and should therefore remain stable over a long period of time. Furthermore, by introducing the public view, the complexity and heterogeneity of the intra-organizational process and IS architecture are effectively concealed, what allows us to concentrate on the artifacts which the business partner need to agree upon. The forming of public and private views is known from approaches for distributed workflow management, e.g. [72], [85], [98] current extensions of process modeling [15], [33], [65], and B2B standards [59], [66], but has been limited to the process layer so far. In our service based architecture for B2G collaboration we adopt this concept to all architecture layers.

Concerning the process layer, the public process is derived from legislative directives, procedures, and regulations. Subsequently, the artifacts of the public process are supposed to be implemented on the basis of a multi-layer, service based IS architecture. From an information perspective, it means to deduce business documents being exchanged between the partners from the public process. From a functional perspective, appropriate public business 
services have to be defined, which are supposed to coordinate the internal workflows and to synchronize the information statuses by the exchange of business documents.

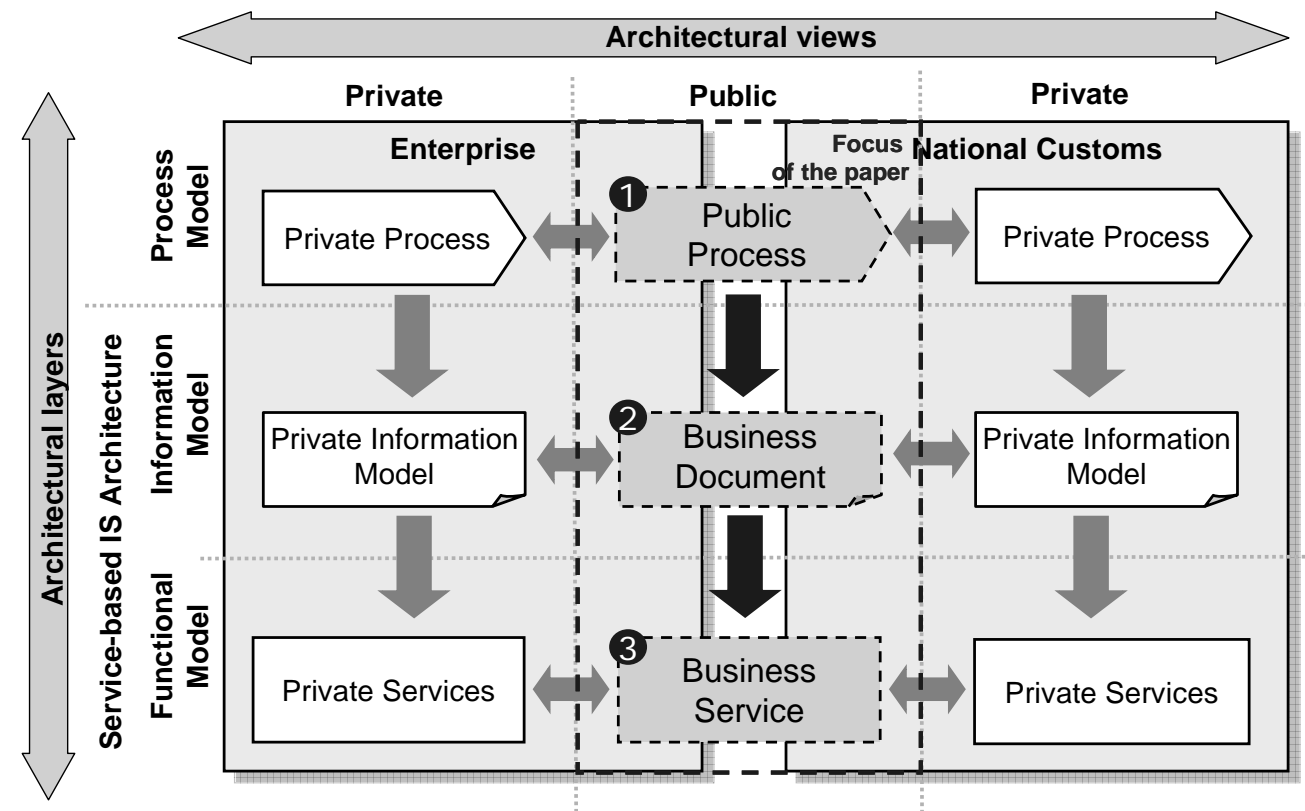

Figure 5: Service Based Architecture for B2G Collaboration

It is important to mention that our service based architecture for B2G collaboration follows a distributed [4], peer-topeer approach [85] without any central components for controlling process coordination and system communication. Coordination is performed purely by means of an agreement regarding syntactic, semantic, and pragmatic aspects on the public artifacts of the process and the IS layer (cp. [43], [64]) guaranteeing a high level of development and operational autonomy [68] as well as loose coupling [8].

\subsection{Methodology Outline}

The following paragraph gives a description of our methodological top-down approach for the systematic derivation of public artifacts which we intend to apply later on in the eCustoms scenario. There are three major, mutually referring activities our approach consists of: (1) definition of the public process, (2) elaboration of the information and document model, and (3) specification of the business service.

Beginning with the process layer, a public process model has to be established by conducting a scenario specific requirements analysis. Representing a view of the entire inter-organizational process, the public process describes the activity flow and the interaction between business partners. The public process, which conceals details of internal private processes, also depicts the different roles involved in the collaboration and their specific responsibilities and functions with regard to the collaboration scenario. A major concern is dedicated to the public interaction model. It further details the interaction between business partners by providing a transaction model with functional and qualitative aspects as necessary input for deriving the design elements for the service based IS layer. While the functional aspects of the interaction are described by sending and receiving activities plus the corresponding request and response documents, the qualitative aspects are determined by linking quality of service parameters, conditions and constraints, such as time to respond, level of security or reliability, costs etc., to these activities and documents. Finally, a model of the public business objects which the business documents are composed of needs to be elaborated. It establishes a common terminology of the collaborative scenario serving as a basis for aligning different semantic meanings of business partners.

The public business object model acts as a starting point for the CCTS compliant Business Information Entity modeling. This implies the definition of different types of BIEs (cp. Section 3.1) by providing a unique identifier and version information, cardinality, an appropriate business data type, the dictionary entry name, an informal description, and the business terms. Thereafter, the document assembly corresponds to the aggregation of business information entities to business documents. A business document is bipartite, consisting of a header and the payload, which in turn aggregates business information entities. The business document is the CCTS compliant representation of the request and response messages specified in the public interaction model on the process layer. As already mentioned, the business documents are supposed to be the input and output parameters of the corresponding business service. For defining a business service, we follow the service topology of [56] and apply a message centric service design [35], [79]. 
The approach of deriving deployable artifacts is twofold. First, the logical model of each business document has to be translated into a corresponding XML schema document by relying on the UN/CEFACT Naming and Design Rules. Second, the logical model of the business service has to be translated into a WSDL interface description. Based on this WSDL interface description the business service can be implemented as Web Services in an arbitrary programming platform following a 'contract-first' paradigm [74]. The stepwise approach for deriving deployable artifacts for a service based architecture for B2G collaboration is depicted in Figure 6.

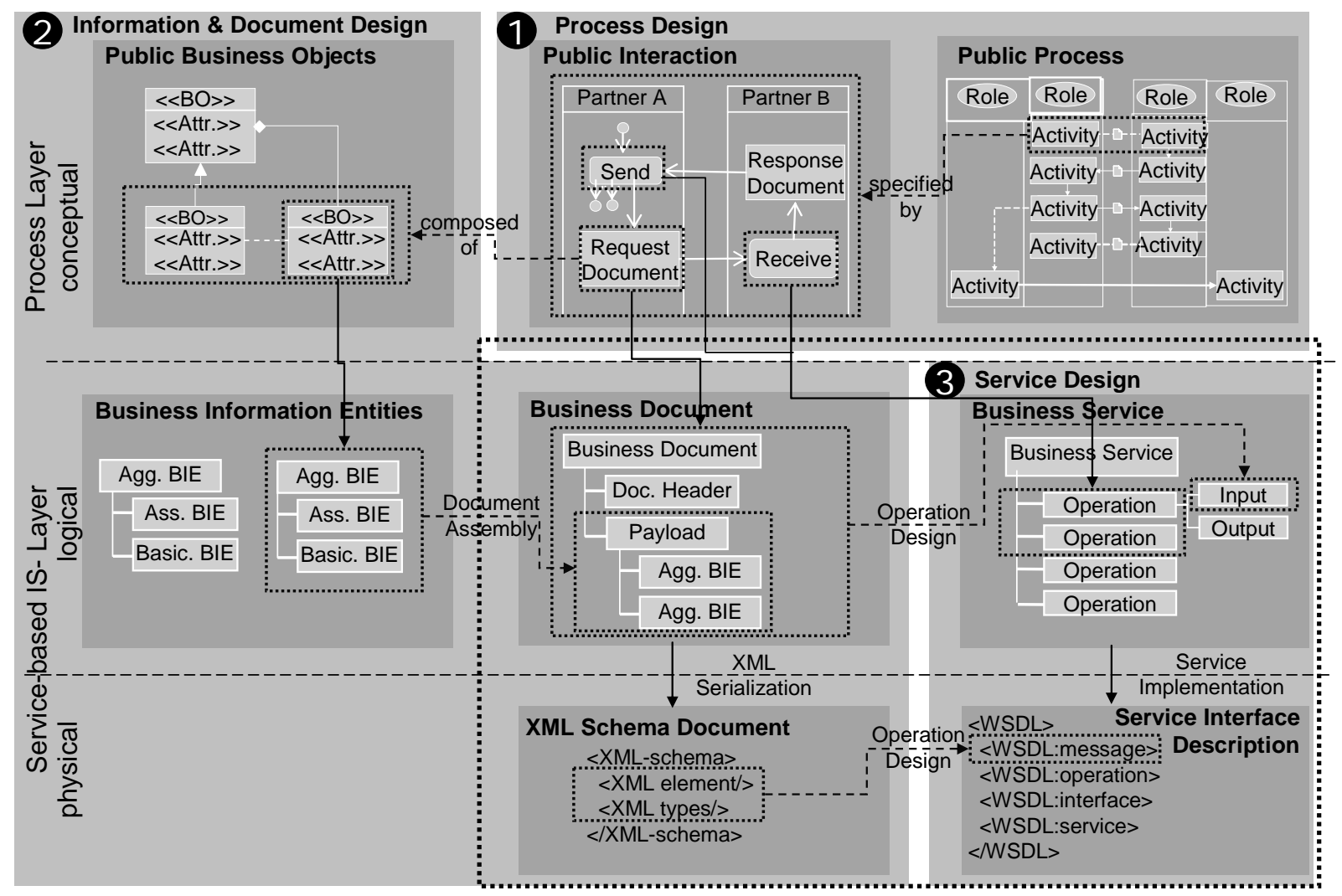

Figure 6: Stepwise Approach to Deriving Deployable Artifacts

\section{Application of the Approach to an eCustoms Scenario}

\subsection{Process Model of the Excise Control and Movement System}

The Excise Movement and Control System (EMCS) is a computerized system supporting the monitoring of excise goods movements (e.g. alcohol, tobacco and energy products) between EU member states under duty suspension [19] and so implicitly stipulating the declaration process of excise movements. The objective of employing EMCS is to replace the paper documents that are currently accompanying these movements (the Administrative Accompanying Document (AAD)) by electronic business documents from the consignor to the consignee via the administrations of the EU member states concerned.

The advantages of EMCS are twofold [21]: (1) for businesses it means faster discharge of the movement guarantees and a reduction in the administrative burden; (2) for the member states administrations it provides a better view on ongoing movements of excise goods, a decrease of the risk of fraud, and better targeting of control efforts.

The excise movement declaration process described in the following is based on the Functional Excise System Specifications [20] and applied to the scenario which is investigated in the Beer Living Lab of the ITAIDE project (see chapter 1.2), where beer as an excise liable good is transported from the Netherlands to the United Kingdom. It is for this reason why the process is to be executed in the EMCS as conceived by the European Commission.

Figure 7 illustrates the overall excise movement declaration process in a simplified form, i.e. only concentrating on the settlement of the declaration statements. In our example, the consignor is a beer brewery in the Netherlands, which submits a draft e-AAD to the Dutch Tax and Customs Authority (DTA). Acceptance or validation of the e-AAD is conducted by DTA as the customs office of dispatch by automatically checking the declaration data - most notably the excise numbers of both consignor and consignee - against the reference data stored in the System for Exchange 
of Excise Data (SEED). If everything proves to be correct, a unique AAD Registration Code (ARC) is appended to the initial e-AAD, which is then immediately sent back to the consignor for evidence purposes.

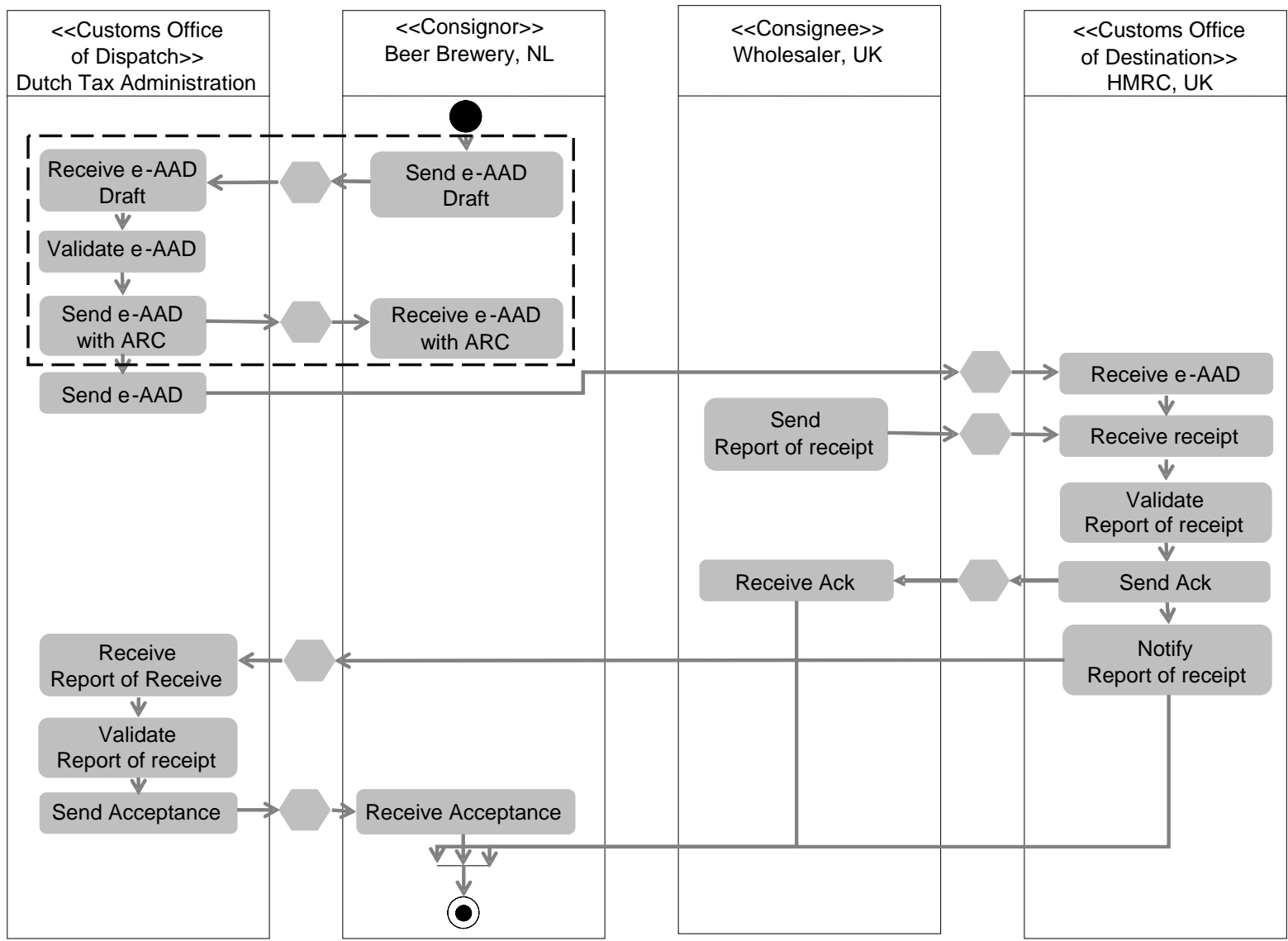

Figure 7: Excise Movement Declaration Exemplifying a B2G and G2G Collaboration Process

Subsequently, the DTA transmits the e-AAD to the designated customs office of destination, in this case to HM Revenue \& Customs (HMRC) in the UK, which in turn forwards the e-AAD to the consignee (here: Wholesaler, UK). After the consignee has submitted a report of receipt including detailed quantities, HMRC validates the report of receipt by checking the positions and quantities and sends an acknowledgement back to the consignee. HMRC then transmits the report of receipt to the DTA, who is now able to verify the correct excise movement. Finally, DTA forwards the report of receipt to the consignor.

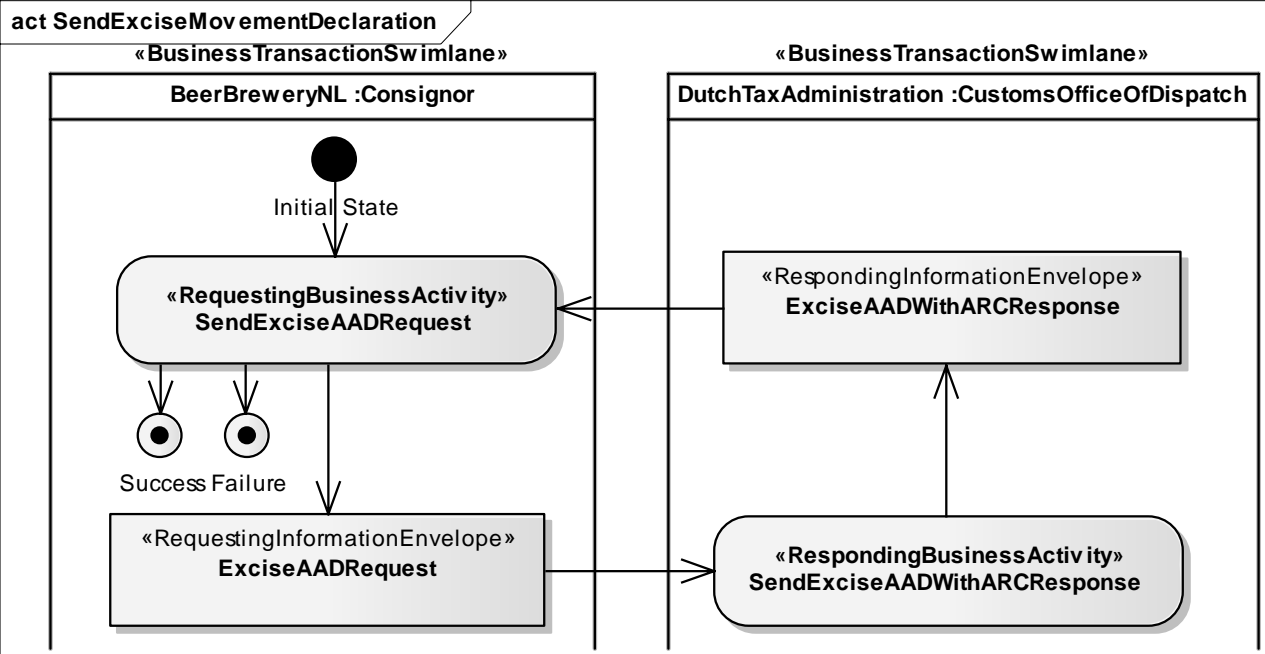

Figure 8: Initial Excise Movement Declaration Process 
Each one of the bilateral interactions can then be described in more detail by means of an interaction model as illustrated in Figure 8. The model is represented by an UML activity diagram, in which a single transaction between two business partners is depicted, i.e. the information exchange between them (being either unidirectional or bidirectional). In our case, we mapped the submission of the draft e-AAD (IE 815, Submitted Draft of e-ADD, [20] p. 61 ) and the subsequent confirm (IE 801, e-AAD, [20] p. 51). The interaction is bidirectional consisting of a so-called 'Requesting Business Activity' sending the initial excise movement declaration on behalf of the consignor and, thereupon, the 'Responding Business Activity' returning the confirmed e-AAD together with the appended ARC from the customs administration.

The 'ExciseAADRequest' business document as depicted in the interaction model in Figure 8 consists of a header and a corresponding payload section containing the content related business information entities. The structure (relationships) and content (attributes) of the header and payload section of the 'ExciseAADRequest' will be depicted in the following step, with the information entities enclosed according to CCTS.

\subsection{Document Model for Excise Movement Declaration}

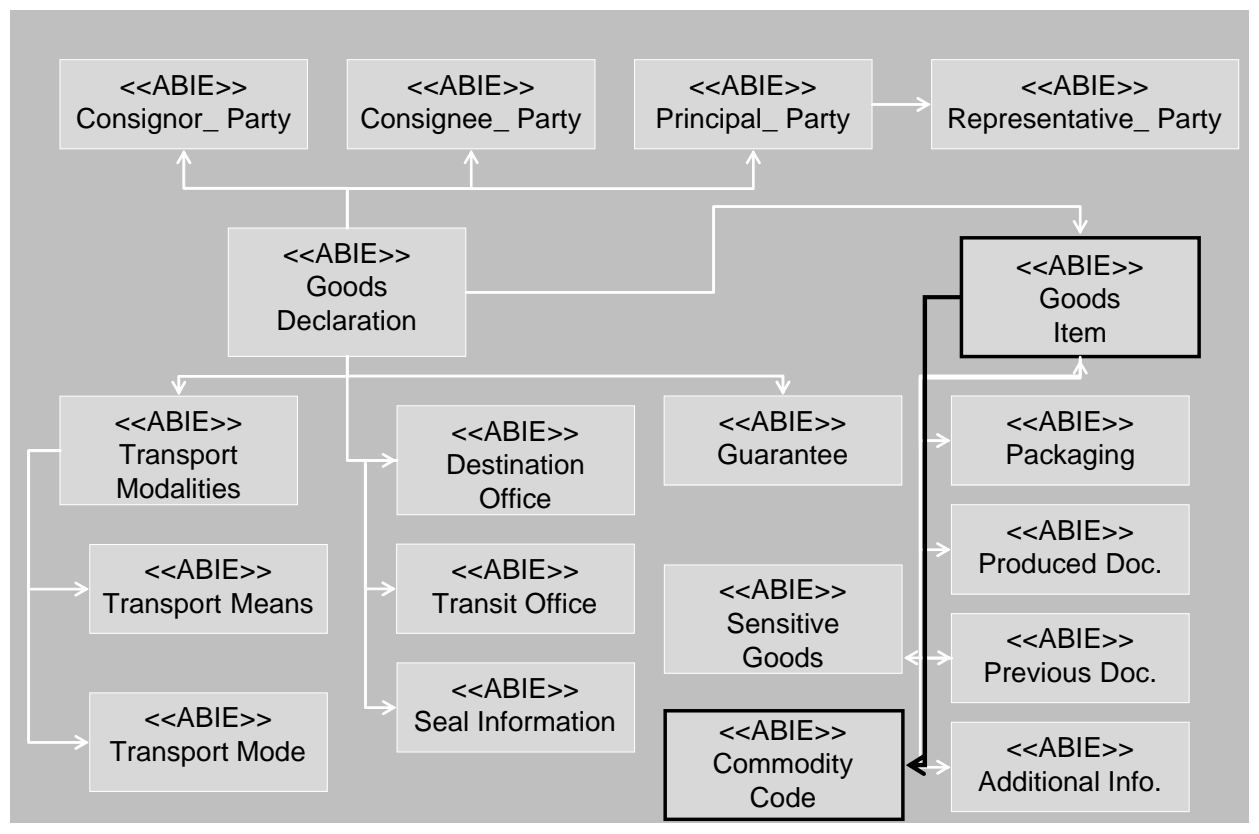

Figure 9: SAD for Transit Procedures Adapting [25]

Regarding European customs procedures, the Single Administrative Document (SAD) [24] issued by the European Directorate for Taxation and Customs (TAXUD) is obligatory for goods declaration as imposed by the Community Customs Code (Council Regulation (EEC) No 2913/92). The SAD is used for import of goods from countries outside the EU, export of goods to countries outside the EU, as well as transit of goods under customs control from the point of arrival in the EU either to the point of duty payment in a different member state or to the point of export from a different member state. Hence, the SAD adheres to the Single Window Access concept on the document level.

Table 3: SAD Transit vs. ECMS Message Gap Analysis

\begin{tabular}{|l|l|l|l|}
\hline \multicolumn{2}{|c|}{$\begin{array}{c}\text { IED Transit } \\
\text { [25] }\end{array}$} & \multicolumn{1}{c|}{ [20] } & Cardinality \\
\hline Field Name & Cardinality & Field Name & \\
\hline Goods Item & & E-AAD Body & Required \\
\hline Sequential Number & Conditional & Body Record Unique Reference & Required \\
\hline Quantity & Conditional & Quantity & \\
\hline Trade Description & Required & & \\
\hline Container Number & Conditional & & Conditional \\
\hline Gross Mass & Required & Gross Weight & Required \\
\hline Net Mass & Required & Net Weight & Required \\
\hline Commodity Code & Required & CN Code & Required \\
\hline & & Excise Product Code & Conditional \\
\hline
\end{tabular}


Previous work conducted by the European Committee of Standardization / Information Society Standardization System (CEN/ISSS) modeled SAD in an electronic, CCTS compliant way, enriched with the business process contexts export, import, and transit. Figure 9 shows the SAD for transit procedures in a reduced manner on class level [25]. Analogous work has been done for export and import procedures.

However, EMCS messages are not based on the SAD data model, but on their own data model. For the highlighted parts of Figure 9, Table 3 compares some important fields of the SAD Transit Message with the corresponding ECMS Message (IE815: Submitted draft of e-AAD).

Instead of implementing the native EMCS data model according to [20], we enhance the SAD data model with EMCS required fields using the context driver principle. In doing so, we continue the effort started by CEN/ISSS and introduce an additional business process context value for excise movement. Table 4 depicts an excerpt (omitting some BBIEs and ABIEs due to space limitations) of the CCTS compliant modelling of the ABIE 'Goods Item. Details' with the corresponding context values excise movement (EXMO) and transit declaration (TRDE)

Table 4: CCTS Compliant ABIE ‘Goods Item’

\begin{tabular}{|c|c|c|c|c|c|c|}
\hline \multicolumn{7}{|c|}{ CCTS-compliant ABIE 'Goods Item. Details' } \\
\hline $\begin{array}{l}\text { Business } \\
\text { Process }\end{array}$ & $\begin{array}{l}\text { BIE } \\
\text { Type }\end{array}$ & $\begin{array}{l}\text { Object Class } \\
\text { Term }\end{array}$ & Property Term & $\begin{array}{c}\text { Representation Term I } \\
\text { Business Data Type }\end{array}$ & & $\begin{array}{l}\text { rence } \\
\text { TRDE }\end{array}$ \\
\hline $\begin{array}{l}\text { EXMO, } \\
\text { TRDE }\end{array}$ & BBIE & Goods Item & Sequential Number & Numeric & 1 & $0 . .1$ \\
\hline $\begin{array}{l}\text { EXMO, } \\
\text { TRDE }\end{array}$ & BBIE & Goods Item & Total Item & Quantity & 1 & 0.1 \\
\hline TRDE & $\mathrm{BBIE}$ & Goods Item & Trade Description & Text & 0 & 1 \\
\hline TRDE & BBIE & Goods Item & Container Number & Quantity & 0 & 0.1 \\
\hline $\begin{array}{l}\text { EXMO, } \\
\text { TRDE }\end{array}$ & BBIE & Goods Item & Gross Mass & Measure & 0.1 & 1 \\
\hline $\begin{array}{l}\text { EXMO, } \\
\text { TRDE }\end{array}$ & BBIE & Goods Item & Net Mass & Measure & 1 & 1 \\
\hline EXMO & $\mathrm{BBIE}$ & Goods Item & Product Code & Excise Product_Code & 1 & 0 \\
\hline EXMO & $\mathrm{BBIE}$ & Goods Item & Alcoholic Strength & Measure & $0 . .1$ & 0 \\
\hline $\begin{array}{l}\text { EXMO, } \\
\text { TRDE }\end{array}$ & ASBIE & Goods Item & Product Class & Commodity_Code & 1 & 1 \\
\hline
\end{tabular}

By selecting a distinct business context value - in our case 'EXMO' - and applying the UN/CEFACT Naming and Design Rules, a corresponding XML schema can be derived. In this context configuration, the BBIEs 'Trade Description. Text' and 'Container Number. Quantity' are omitted. All BIEs can be typed by Business Data Types, which are defined in a separate XML schema. For each ASBIE, a separate ComplexType definition has to be defined. The following code excerpt in Figure 10 presents the XML schema for 'Goods Item. Details':

<xsd:element name="GoodsItem" type="ram:GoodsItemType"/>

$<x$ sd:element name="CommodityCode" type="ram:CommodityCodeType"/>

$<$ xsd:complexType name="GoodsItemType"> <!--ABIE-->

$<x$ sd:sequence $>$

$<$ xsd:element name="SequentialNumber" type="bdt:NumericType"/> <!--BBIE-->

$<x$ sd:element name="Totalltem" type="bdt:QuantityType"/> <!--BBIE-->

$<x$ sd:element name="GrossMass" type="bdt:MeasureType" minOccurs="0"/> <!--BBIE-->

$<$ xsd:element name="NetMass" type="bdt:MeasureType"/><!--BBIE-->

$<x$ sd:element name="ProductClass" type="bdt:ExciseProductCodeType"/> <!--BBIE-->

$<x$ sd:element name="AlcoholicStrength" type="bdt:MeasureType" minOccurs="0"/> <!--BBIE-->

$<x$ d:element name="DesignatedCommodityCode" type="ram:CommodityCodeType"/> <!--ASBIE-->

$</ x s d$ :sequence $>$

$</ x s d: c o m p l e x T y p e>$

$<$ xsd:complexType name="CommodityCodeType" $><!--A B \mid E-->$

$<x s d:$ sequence $>$

<xsd:element name="CombinedNomenclature" type="bdt:CombinedNomenclatureCodeType"/> $</ x$ sd:sequence $>$

$</ x s d:$ complexType $>$

Figure 10: XML Schema Code Excerpt for ABIE 'Goods Item. Details' 
For each BBIE typed by a specific code list a separate XML schema file specifying values that are allowed has to be created. In the case of the BBIE 'Product Class. Excise Product_Code' the code list for some sample values is given in Figure 11.

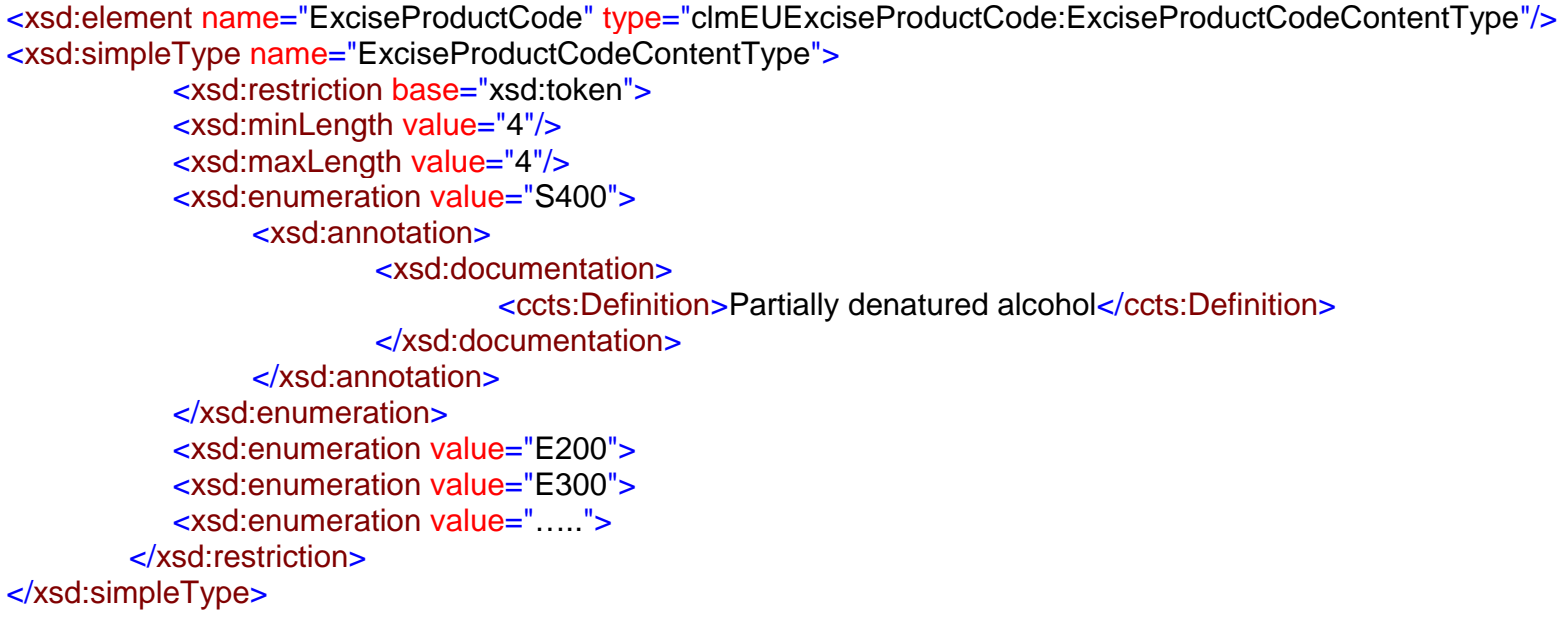

Figure 11: Code List for Excise Product Code

Having once finished the BIE modelling, the business document is assembled by combining the Standardized Business Document Header (SBDH) with the actual payload, which encompasses all the relevant BIEs (cp. Figure 12).

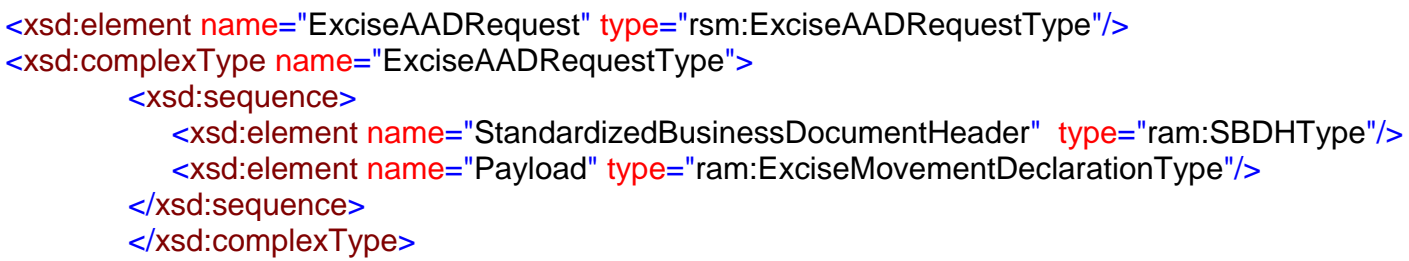

Figure 12: XML Schema for the 'ExciseAADDRequest' business document

The content of the 'SBDHType' and the 'ExciseMovementDeclarationType' are further detailed in Figure 13. The 'Excise MovementDeclaration' contains only the ABIE 'Goods. Declaration', which in turn contains some BIEs and all the relating ASBIEs such as 'Goods Item' as we have modeled above.

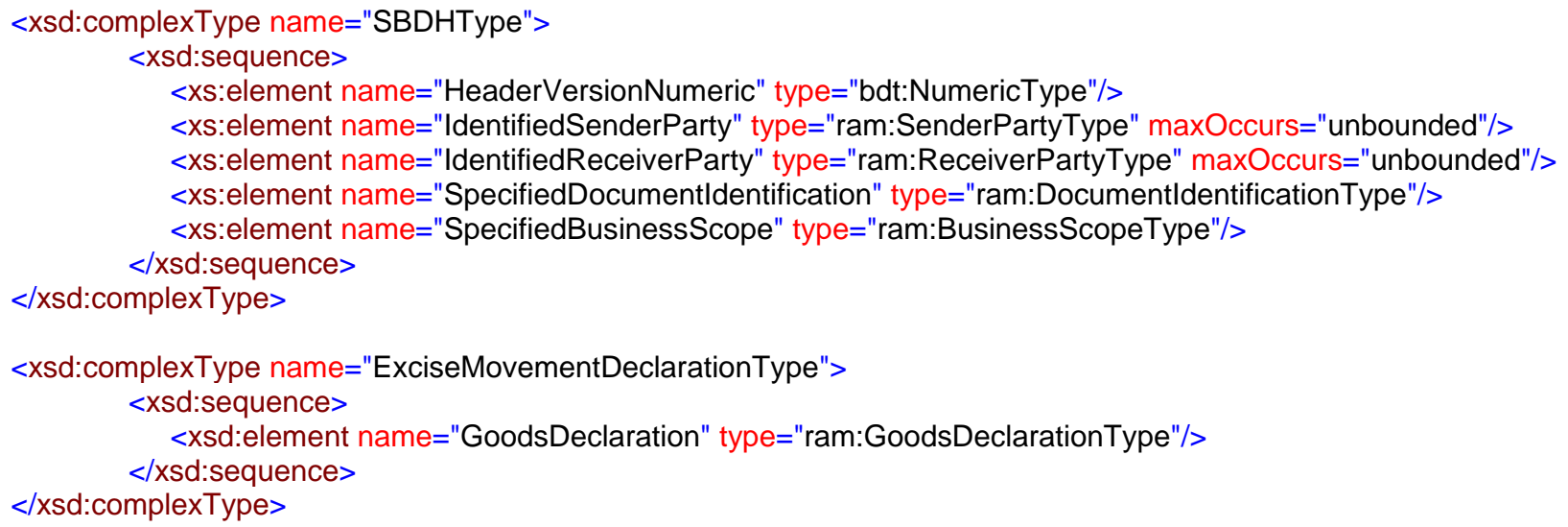

Figure 13: XML Schema for the 'SBDHType' and 'ExciseMovementDeclarationType'

\subsection{Service Model: A Standardized Interface to ECMS}

The design of the data and the message model has been completed by the previous paragraph, thus according to the service topology of [56] only the operation design of the business service remains to be discussed. A major decision has to be taken on whether to apply strongly typed versus generic operations [97] p. 214. While generic operations may better cope with upcoming changes in the business document model than strongly typed interfaces, 
the loss of semantics outweighs the advantage when it comes to design-time orchestration and run-time maintenance issues [46]. Hence, we follow a strongly typed interface design. In doing so, the operations directly reflect the interactions as defined in the interaction model. Taking the example of Figure 8, we have a two-way message exchange in terms of a request/response paradigm.

According to the explanations of [21] p. 8, a request of an e-AAD is automatically validated and the response is sent back to the consignor immediately. Therefore, we deal with a synchronous request-respond interaction style, where the response is transmitted as a return value. Thus, our Web Service invoked by a business partner features an operation 'receiveExciseAADRequest', which takes the 'ExciseAADRequest' as an input and returns the 'ExciseAADWithARCResonse' as the output parameter. The design of the WSDL document includes three major steps defining the PortType, the Binding, and the Service specification.

The three steps are as follows: (1) With the definition of the PortType the operation signature is specified. This means that the operations as well as the input and the output parameter are indicated in terms of an abstract service definition, where no transport-protocol specific information is supplied. (2) The Binding specification refers to a concrete transport protocol (e.g. SOAP, HTTP-Get, HTTP-Post). Our implementation prototype is based on a SOAP protocol binding. Additionally, the WSDL style and encoding has to be amended. In our case, we adopt the document/literal wrapped style/coding pattern to be WS-I compliant and, hence, ensure technical interoperability [10]. (3) Finally, the Service specification concludes the process with the designation of the URL where the service can be invoked. The corresponding WSDL code is given in the following fragment:

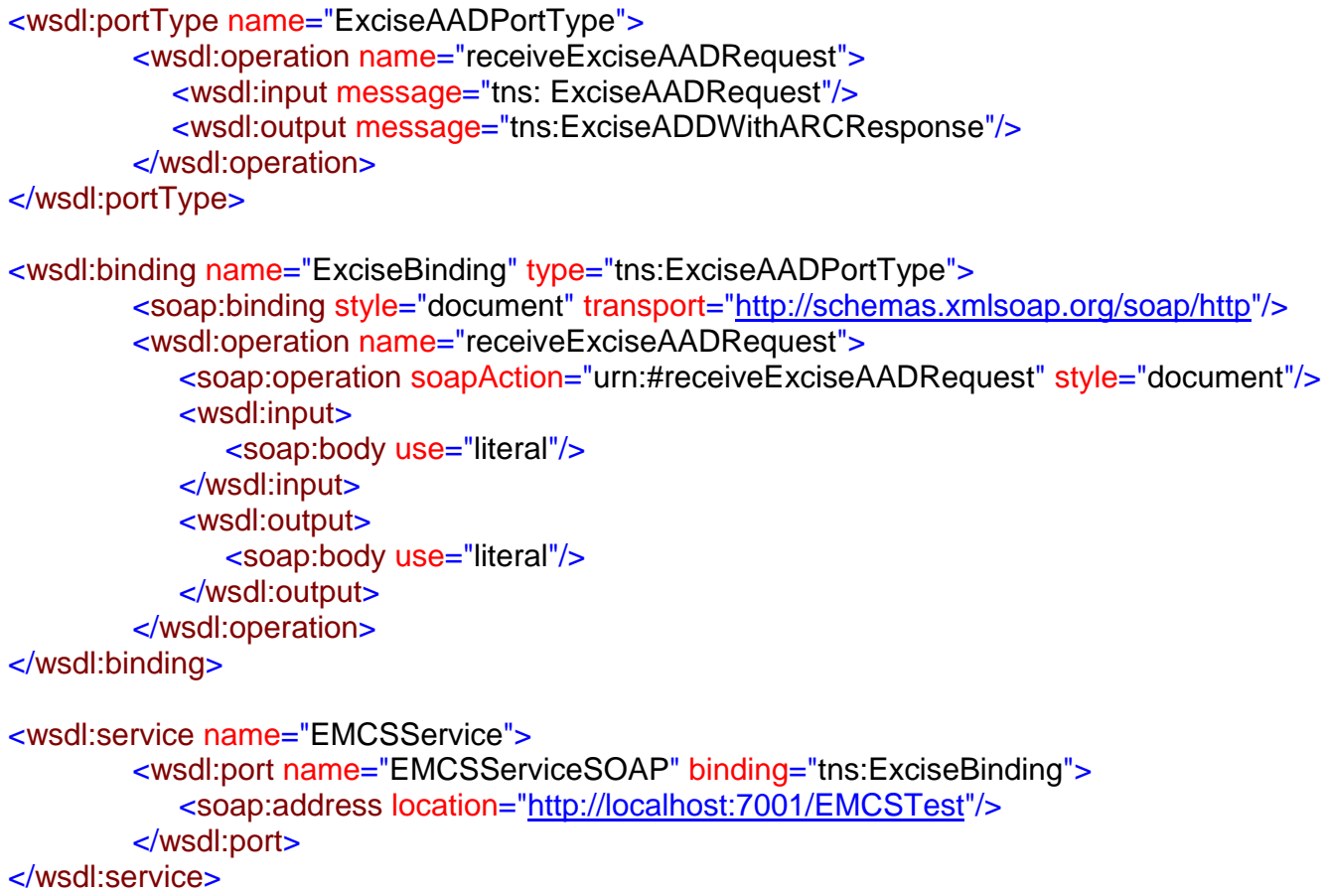

Figure 14: WSDL Code Fragment of the Excise Movement Declaration Business Service

\section{Conclusion}

\subsection{Research Contribution}

Based on the research questions raised in Chapter 2.4, the article at hand provides two essential artifacts in terms of Design Science research. Firstly, we outline an architecture model for 'Collaborative eGovernment', which relies on the principles of service orientation, and distinguishes between artifacts of the information, service and process layer. We have paid special attention to the public artifacts of each of these layers, which the economic operators and the governmental authorities have to agree upon. Secondly, we propose a methodological approach how to derive customizable business documents and services as the main design elements of a service based architecture from the requirements of a public process as imposed by administrative regulations. Therefore, our approach follows the document engineering approach as defined by [31] and further refines it by adopting CCTS and the context driver principle fostering reuse and customization on business document level. Finally, we embed these business documents in the WSDL interface description of a publicly accessible Web Service. In doing so, we contribute to the eGovernment integration efforts and interoperability postulate of EU initiatives [23]. 
Following a Design Science research approach, both the architecture and the methodological approach are applied in a real-life B2G scenario in the eCustoms domain. In this respect, we have illustrated the intra-EU excise movement declaration process of a European beer producer according to the EMCS specification and have modeled one of the essential customs documents exchanged between the partners, the e-AAD, in accordance with CCTS and its context driver principle. Consequently, we are able to show how the context mechanism enables the adaptation of business documents to particular business contexts (see Chapters 5.1 and 5.2). In a last step, we have derived a corresponding service model for the electronic exchange of the e-AAD between the economic operator and customs administration and have implemented the service interface as a WSDL document (Chapter 5.3).

Our approach is defined generically for being adoptable to other eCustoms scenarios, such as the forthcoming Automated Export System and the Automated Import System, contributing to the interoperability objectives of the EU in the eGovernment domain. Consequently, the article does not only offer an added value to the interoperability discussion in information science research but, moreover, to the practical challenge of a harmonized European-wide eGovernment framework.

\subsection{Limitations \& Implications}

The insights we have gained by our research should be critically reflected by considering the limitations of our approach in order to be able to draw the right conclusions and recommendations for future research and standardization efforts.

Concerning the UN/CEFACT standards, we have encountered some difficulties when applying them in the excise movement scenario. For instance, it has been difficult to apply the UN/CEFACT standard for Core Component Message Assembly because of its draft status. Moreover, the reference to the Core Component Library has revealed that the elements contained are very generic, so that most BIEs of the eCustoms domain still have to be submitted to the Core Component Library. Although the CCTS in Version 3.0 appeared as a mature and thoughtful standard, we find it hard to gain any benefit from the conceptual distinction between Core Components and Business Information Entities. Regarding the context driver principle, we perceived the definition of the context categories and the corresponding context value lists as work in progress, which still needs further elaboration and evaluation. Furthermore, we reached the conclusion that the increasing complexity in the UN/CEFACT standards stack may hinder a broader dissemination and therefore necessitates simplification. Eventually, ensuring consistency between and harmonization of the different UN/CEFACT sub-standards, namely the alignment between the UN/CEFACT CCTS 3.0 and NDR 2.0 as well as between UN/CEFACT CCMA Draft, SBDH 1.3 and CCTS 3.0, remains a challenge.

As designing and customizing business documents on the basis of the UN/CEFACT standards manually is considered to be tedious and error-prone, it is desired to have an appropriate tool support for the code generation. Therefore, we favour further evolution of the current research prototypes H2-Toolset and Warp10. Regarding the latter, the requirements and the experience of our case study in the Beer living Lab contribute to the current efforts of the Warp10 development [76].

In terms of Design Science as a research method, the scope of our validation effort has been restricted to a single document in the excise eCustoms scenario. We therefore strive to broaden the scope to other eCustoms scenarios, for instance the export scenario as depicted in the Food Living Lab of the ITAIDE project. In doing so, we aim at refining our methodological approach iteratively.

\section{Acknowledgments}

The research is part of the ITAIDE integrated project (nr. 027829), which is funded by the 6th Framework Information Society Technology (IST) Program of the European Commission.

We would like to gratefully acknowledge the support of Gunther Stuhec, Chair of UN/CEFACT Techniques and Methodologies Group (TMG), whose expertise in all UN/CEFACT related topics was very helpful. The results from the productive collaboration with Gunther Stuhec's team significantly contributed to our research effort.

\section{References}

[1] G. Alonso, F. Casati, H. Kuno, and V. Machiraju, Web Services: Concepts, Architectures and Applications. Berlin: Springer, 2003.

[2] A. B. Arntzen and A.-M. Krosgrud, Web-Services Architecture: The Solution For E-Government Applications, in Proceedings of the International Conference on E-Learning, E-Business, Enterprise Information Systems, EGovernment and Outsourcing, 2006, pp. 49-54.

[3] Z. Baida, B. Rukanova, J. Liu, and Y.-H. Tan, Rethinking EU Trade Procedures - The Beer Living Lab, in Proceedings of the 20th Bled eCommerce Conference, 2007, pp. 1-14. 
[4] B. Bauer, J. P. Müller, and S. Roser, A Decentralized Broker Architecture for Collaboritive Business Process Modelling and Enactment, Proceedings of the 2nd International Conference on Interoperability of Enterprise Systems and Architecture, pp. 115-126, 2006.

[5] J. Becker, C. Janiesch, and D. Pfeiffer, Context-based Modeling - Conceptualization of a Novel Modeling Approach and Application for the Design of Business Documents, in Proceedings of the 11th Pacific Asia Conference on Information Systems, 2007, p. 143ff.

[6] J. Becker, S. Kramer, and C. Janiesch, Ein Ansatz für das Variantenmanagement elektronischer Geschäftsdokumente, in Multikonferenz Wirtschaftsinformatik 2008, 2008, pp. 837-848.

[7] E. Brousseau, EDI and inter-firm relationships: toward a standardization of coordination processes?, Information Economics and Policy, vol. 12, no. 6, pp. 319-347, 1994.

[8] C. Bussler, P2P in $\mathrm{B} 2 \mathrm{BI}$, in Proceedings of the 35th Hawaii International Conference on System Sciences (HICSS 2002), 2002, pp. 302-311.

[9] C. Bussler, The Role of B2B Engines in B2B Integration Architectures, SIGMOND Record, vol. 31, no. 1, pp. 6772, 2002.

[10] R. Butek. (2003) Which style of WSDL should I use? IBM. [Online]. Available: http://www106.ibm.com/developerworks/library/ws-whichwsdl/.

[11] J. Damsgaard and D. Truex, Binary trading relations and the limits of EDI standards: the Procrustean bed of standards, European Journal of Information Systems, vol. 9, no. 3, pp. 173-188, 2000.

[12] E. M. Daniel and A. White, The future of inter-organisational system linkages: findings of an international Delphi study, European Journal of Information Systems, vol. 14, no. 2, pp. 188-203, 2005.

[13] E. M. Daniel, A. White, and J. Ward, Exploring the role of third parties in inter-organisational web service adoption, Journal of Enterprise Information Management, vol. 17, no. 5, pp. 351-360, 2004.

[14] E. Diedrich, D. Schmidt, and M. Wimmer, A Three Dimensional Framework to Realize Interoperability in Public Administrations, in Workshop on Semantic Web for eGovernment 2006, 2006, pp. 54-59.

[15] B. Elvesater, A. Hahn, A. Berre, and T. Neple, Towards an Interoperability Framework for Model-Driven Development of Software Systems, in Proceedings of the 1st International Conference on Interoperability of Enterprise Software and Applications (INTEROP-ESA'05), Geneva, Switzerland, 2005, pp. 409 - 420.

[16] T. Erl, Service-Oriented Architecture. New York: Prentice Hall, 2005.

[17] European Commission, Communication from the commission to the council, the European parliament, the European economic and social committee and the committee of the regions: The role of eGovernment for Europe's future, Brussels, 2003

[18] European Commission, Electronic Customs Multi-Annual Strategic Plan (MASP) Rev. 8, Directorate General for Taxation and Customs Union, Brussels, Belgium, 2007.

[19] European Commission. (2008) Excise Movement and Control System (EMCS). Taxation and Customs of the European Commission. [Online]. Available: http://ec.europa.eu/taxation customs/taxation/excise duties/circu lation control/index en.htm.

[20] European Commission, Functional Excise System Specifications (FESS) 2.13, Directorate General for Taxation and Customs Union, Brussels, Belgium, 2007.

[21] European Commission, Functional Excise System Specifications: Excise Movement and Control System, Directorate General for Taxation and Customs Union, Brussels, Belgium, 2006.

[22] European Commission, i2010 eGovernment Action Plan: Accelerating eGovernment in Europe for the Benefit of all, Brussels, Belgium, 2006

[23] European Commission. (2003) Linking up Europe: The Importance of Interoperability for eGovernment Services. [Online]. Available: http://ec.europa.eu/idabc/servlets/Doc?id=1675.

[24] European Commission, Single Administrative Document (SAD) - COMMISSION REGULATION (EC) No 2286/2003, European Commission, Brussels, Belgium, 2003

[25] European Committee for Standardization, SAD Transit Declaration - Implementation model (CWA 15066), European Committee for Standardization (CEN), Brussels, Belgium, 2004.

[26] G. Feuerlicht, Design of service interfaces for e-business applications using data normalization techniques, Information Systems and E-Business Management, vol. 3, no. 4, pp. 363-376, 2005.

[27] R. T. Fielding, Architectural Styles and the Design of Network-based Software Architectures Irvine: University of California, 2000

[28] O. Fodor and H. Werthner, Harmonise: A Step Toward an Interoperable E-Tourism Marketplace, International Journal of Electronic Commerce, vol. 9, no. 2, pp. 11-39, 2004.

[29] R. D. Galliers, Towards a flexible information architecture: integrating business strategies, information systems strategies and business process redesign, Journal of Information Systems, vol. 3, no. 3, pp. 192-213, 1993.

[30] R. J. Glushko and T. McGrath, Document Engineering - Analyzing and Designing Documents for Business Informatics and Web Services. Boston: MIT Press, 2005

[31] R. J. Glushko and T. McGrath, Document Engineering: Analyzing and Designing the Semantics of Business Service Networks, in IEEE EEE-05 International Workshop on Business Services Networks, 2005

[32] S. Gregor, The Nature of Theory in Information Systems, MIS Quarterly, vol. 30, no. 3, pp. 611-642, 2006.

[33] U. Greiner, C. Legner, S. Lippe, and K. Wende, Business Interoperability Profiles: Relating Business Interoperability Issues to Technical Interoperability Solutions, in Proceedings of the 3rd International Conference on Interoperability for Enterprise Software and Applications (I-ESA 2007), 2007.

[34] J. I. Hagel and J. S. Brown, Your Next IT Strategy, Harvard Business Review, vol. 79, pp. 105-113, 2001.

[35] M. Henkel and J. Zdravkovic, Approaches to Service Interface Design, in Proceedings of the Web Service Interoperability Workshop, Geneva, Switzerland, 2005. 
[36] A. R. Hevner, S. T. March, J. Park, and S. Ram, Design Science in Information Systems Research, MIS Quarterly, vol. 28, no. 1, pp. 75-105, 2004.

[37] IDABC, European Interoperability Framework for Pan-European eGovernment Services, EU Enterprise and Industry Commission, 2004.

[38] ISO. (2005) ISO 15000-5: Electronic Business Extensible Markup Language (ebXML) - Part 5: ebXML Core Components Technical Specification, Version 2.01. ISO. [Online]. Available: http://www.iso.org/iso/iso catalogue/ catalogue tc/catalogue detail.htm?csnumber=41022.

[39] ITAIDE, Beer Living Lab - Final Report, Brussels, Belgium, Deliverable D5.1:5, 2008

[40] ITAIDE. (2006) Information Technology for Adoption and Intelligent Design for E-Government (project nr. 027829). [Online]. Available: http://www.itaide.org/.

[41] C. Janiesch and S. M. Thomas, Business Document Taxonomy - Comparison of the State-of-the-art and Recommendations for Future Applications, Interoperability in Business Information Systems, vol. 1, no. 2, pp. 5978, 2006.

[42] R. Klischewski, Information integration or process integration? How to achieve interoperability in administration, in Proceedings of EGOV 2004, Berlin, 2004, pp. 57-65.

[43] H. Kubicek, The Organization Gap in Large-Scale EDI Systems, in Scientific Research on EDI "Bringing Worlds Together" (R. J. Streng, C. F. Ekering, E. van Heck, and J. F. H. Schultz, Eds.). Amsterdam: Samsom, 1992, pp. 11-41.

[44] K. Layne and J. Lee, Developing fully functional e-Government: A four stage model, Government Information Quarterly, vol. 18, no. 2, pp. 122-136, 2001

[45] C. Legner and R. Heutschi, SOA Adoption in Practice - Findings from Early SOA Implementations, in Proceedings of the 15th European Conference on Information Systems "Relevant rigor - Rigorous relevance", St. Gallen, Switzerland, 2007

[46] C. Legner and T. Vogel, Leveraging Web Services for Implementing Vertical Industry Standards: A Model for Service-based Interoperability, Electronic Markets, vol. 18, no. 1, pp. 39-52, 2008.

[47] C. Legner and T. Vogel, Service-based Interoperability - Leveraging Web Services for Implementing Industry Standards, in Proceedings of the 20th Bled eConference eMergence, Bled, Slovenia, 2007.

[48] C. Legner and K. Wende, Towards an Excellence Framework for Business Interoperability, in Proceedings of the 19th Bled eConference eValues, Bled, Slovenia, 2006.

[49] A. Lemm, XML-basierte E-Business-Frameworks - Analyse, Konvergenztendenzen und Vergleich: TU Darmstadt / Uni St. Gallen, 2007.

[50] D. S. Linthicum, Next Generation Application Integration: From Simple Information to Web Services. Upper Saddle River, NJ: Addison-Wesley, 2003.

[51] J. Liu, Z. Baida, and Y.-H. Tan, e-Customs Control Procedures Redesign Methodology: Model-Based Application, in Proceedings of the 15th European Conference of Information Systems, St. Gallen, Switzerland, 2007, pp. 93105.

[52] Y. Malhotra, Enterprise Architecture: An Overview. Pittsburgh, PA: University of Pittsburgh, Katz School of Business, 1996.

[53] S. T. March and G. F. Smith, Design and natural science research on information technology, Decision Support Systems, vol. 15, no. 4, pp. 251-266, 1995.

[54] A. McAfee, Will Web Services Really Transform Collaboration?, MIT Sloan Management Review, vol. 46, no. 2, pp. 78-84, 2005

[55] B. Meneklis, A. Kaliontzoglou, C. Douligeris, and D. Polemi, Engineering and Technology Aspects of an eGovernment Architecture Based on Web Services, in Proceedings of the 3rd European Conference on Web Services, 2005, pp. 190-197.

[56] H. R. Motahari Nezhad, B. Benatallah, A. Martens, F. Curbera, and F. Casati, Semi-Automated Adaptation of Service Interfaces, in Proceedings of the 16th International World Wide Web Conference 2007, 2007, pp. 9931002.

[57] M. L. Nelson, M. J. Shaw, and W. Qualls, Interorganizational System Standards Development in Vertical Industries, Electronic Markets, vol. 15, no. 4, pp. 378-392, 2005.

[58] J.-M. Nurmilaakso, P. Kotinurmi, and H. Laesvuori, XML-based-E-business Frameworks and Standardization, Computer Standards \& Interfaces, vol. 28, no. 5, pp. 585-599, 2006.

[59] OASIS, ebXML Business Process Specification Schema Technical Specification v2.0.4, OASIS, Billerica, MA, 2006.

[60] OASIS. (2007) UBL FAQ. [Online]. Available: http://www.oasis-open.org/committees/ubl/faq.php.

[61] H. Österle and D. Blessing, Business Engineering Modell, in Business Engineering vol. $2(\mathrm{H}$. Österle and R. Winter, Eds.). Berlin: Springer, 2003, pp. 65-85.

[62] D. Pentcheva, Context Driven Collaborative Service-oriented Business Process Modeling Berlin: Berlin Institute of Technology, 2007.

[63] P. Ratnasingam, The impact of collaborative commerce and trust in web services, Journal of Enterprise Information Management, vol. 17, no. 5, pp. 382-387, 2004.

[64] K. Reimers, Standardizing the new e-business platform: Learning from the EDI experience, Electronic Markets, vol. 11, no. 4, pp. 231-237, 2001.

[65] S. Roser and B. Bauer, Improving Interoperability in Collaborative Modelling, in Proceedings of the 3rd I-ESA 2007, Madeira Portugal, 2007, pp. 139-150

[66] RosettaNet. (2001) Introduction to RosettaNet. RosettaNet. [Online]. Available: http://www.rosettanet.org/. 
[67] J. Schelp and R. Winter, Business Application Design and Enterprise Service Design: A Comparison, International Journal of Services Sciences (IJSSci), 2007.

[68] M. Schissler, S. Mantel, O. K. Ferstl, and E. J. Sinz, Kopplungsarchitekturen zur überbetrieblichen Integration von Anwendungssystemen und ihre Realisierung mit SAP R/3, Wirtschaftsinformatik, vol. 44, no. 5, pp. 459-468, 2002.

[69] A. Schmidt, CCTS - A Novel Framework for Conceptual Data Modelling, in Proceedings of SIWIS - SWISSITALIAN Workshop on Information Systems, 2007.

[70] J. Scholl and R. Klischewski, E-Government Integration and Interoperability: Framing the Research Agenda, International Journal of Public Administration (IJPA), vol. 30, no. 8-9, pp. 889-920, 2007

[71] C. Schroth, T. Janner, and G. Stuhec, UN/CEFACT Service-Oriented Architecture: Enabling Both Semantic And Application Interoperability, in Kommunikation in Verteilten Systemen - 15. ITG/GI - Fachtagung (KIVS 2007), 2007.

[72] M. Shen and D.-R. Liu, Coordinating Interorganizational Workflows Based on Process-Views, in Proceedings of the 12th International Conference on Database and Expert Systems Applications, Berlin/Heidelberg, 2001, pp. 274-283.

[73] J. Siedersleben, SOA revisited: Komponentenorientierung bei Systemlandschaften, Wirtschaftsinfomatik, vol. 49, pp. 110-117, 2007.

[74] A. Skonnard. (2005) Contract First Service Development. Microsoft. [Online]. Available: http://msdn2.microsoft.com/en-us/magazine/cc163800.aspx.

[75] G. Stuhec. (2006) How to Solve the Business Standards Dilemma - CCTS Key Model Concepts. [Online]. Available: $\quad$ https://www.sdn.sap.com/iri/servlet/prt/portal/prtroot/docs/library/uuid/1b873fc3-0901-0010-f7bc-951 8e1aed0cf.

[76] G. Stuhec, Using CCTS Modeler Warp 10 to Customize Business Information Interfaces, SAP AG, Walldorf, Germany, 2007.

[77] G. Stuhec and M. Crawford. (2006) How to Solve the Business Standards Dilemma - The CCTS Standards Stack. SAP AG. [Online]. Available: https://www.sdn.sap.com/irj/sdn/go/portal/prtroot/docs/library/uuid/30d35ece5c67-2910-64aa-cb331726ee1c.

[78] Y.-H. Tan, S. Klein, B. Rukanova, A. Higgins, and Z. Baida, Information Technology for Adoption and Intelligent Design for e-Government (ITAIDE), 2006

[79] H. M. Teo and W. M. N. W. Kadir, A Comparative Study of Interface Design Approaches for Service-Oriented Software, in Proceedings of the 13th Asia Pacific Software Engineering Conference (APSEC'06), 2006, pp. 147156.

[80] K. Umapathy and S. Purao, A theoretical investigation of the emerging standards for web services, Information Systems Frontier, vol. 9, no. 1, pp. 119-134, 2007.

[81] UN/CEFACT. (2008) UN/CEFACT Core Component Library. [Online]. Available: http://www.unece.org/cefact/co desfortrade/codes index.htm.

[82] UN/CEFACT. (2007) UN/CEFACT Core Components Technical Specification, Version 3.0. UN/CEFACT. [Online]. Available: http://75.43.29.149:8080/download/attachments/3801818/Specification CCTS3p0+2nd+Pu blic+Review+16APR2007.pdf?version=1.

[83] UN/CEFACT. (2007) UN/CEFACT Core Data Type Catalogue. [Online]. Available: http://75.43.29.149:8080/ display/ATG/CDT+Catalogue.

[84] UNECE. (2005) Memorandum of understanding between UNECE and OASIS. [Online]. Available: http://www.unece.org/cefact/cf-plenary/plenary05/cf 05-misc2.pdf.

[85] W. van der Aalst and M. Weske, The P2P Approach to Interorganizational Workflows, in Proceedings of the 13th International Conference on Advanced Information Systems Engineering, 2001, pp. 140-156.

[86] R. Vidgen, D. Francis, P. Powell, and M. Woerndl, Web service business transformation: collaborative commerce opportunities in SMEs, Journal of Enterprise Information Management, vol. 17, no. 5, pp. 372-381, 2004.

[87] W3C. (2004) Web Services Architecture. W3C. [Online]. Available: http://www.w3.org/TR72004/NOTE-ws-arch$20040211 /$.

[88] M. Wimmer, C. Codagnone, and M. Xiaofeng, Developing an E-Government Research Roadmap: Method and Example from E-GovRTD2020, in Electronic Government, 2007, pp. 1-12.

[89] M. Wimmer and R. Traunmüller, Integration - The Next Challenge in e-Government, in Advances in Information and Communication Technology, Wien, 2002, pp. 213-218.

[90] R. Winter and R. Fischer, Essential Layers, Artifacts, and Dependencies of Enterprise Architecture, Journal of Enterprise Architecture, vol. 3, no. 2, pp. 7-18, 2007.

[91] P. Wolf and H. Krcmar, Collaborative E-Government - Bedarfsorientierung in komplexen Unternehmenslagen, in Tagungsband des 9. Internationalen Rechtsinformatik Symposiums, Stuttgart, 2006, pp. 178-185.

[92] P. Wolf and H. Krcmar, Prozessorientierte Wirtschaftlichkeitsuntersuchung für EGovernment, Wirtschaftsinformatik, vol. 47, pp. 337-346, 2005.

[93] Y. Yarimagan and A. Dogac, A Semantic based Solution for the Interoperability of UBL Schemas, submitted for publication, 2008.

[94] H. Yu, Context Driver Principle Karlsruhe: University Karlsruhe, 2007.

[95] K. Zhao, M. Xia, and M. J. Shaw, Vertical E-Business Standards and Standards Developing Organizations: A Conceptual Framework, Electronic Markets, vol. 15, no. 4, pp. 289-300, 2005.

[96] O. Zimmermann, V. Doubrovski, J. Grundler, and K. Hogg, Service-Oriented Architecture and Business Process Choreography in an Order Management Scenario: Rationale, Concepts, Lessons Learned, in Proceedings of OOPSLA'05, 2005, pp. 301-312. 
[97] O. Zimmermann, M. Tomlinson, and S. Peuser, Perspectives on Web Services. Berlin: Springer, 2003.

[98] M. zur Muehlen, J. V. Nickerson, and K. D. Swenson, Developing web services choreography standards - the case of REST vs. SOAP, Decision Support Systems, vol. 40, pp. 9-29, 2005. 